\title{
WestVirginiaUniversity
}

THE RESEARCH REPOSITORY @ WVU

Graduate Theses, Dissertations, and Problem Reports

2017

\section{Productivity Index of Horizontal Gas Well}

Abdullah A. Almuraikhi

Follow this and additional works at: https://researchrepository.wvu.edu/etd

\section{Recommended Citation}

Almuraikhi, Abdullah A., "Productivity Index of Horizontal Gas Well" (2017). Graduate Theses, Dissertations, and Problem Reports. 5081.

https://researchrepository.wvu.edu/etd/5081

This Thesis is protected by copyright and/or related rights. It has been brought to you by the The Research Repository @ WVU with permission from the rights-holder(s). You are free to use this Thesis in any way that is permitted by the copyright and related rights legislation that applies to your use. For other uses you must obtain permission from the rights-holder(s) directly, unless additional rights are indicated by a Creative Commons license in the record and/ or on the work itself. This Thesis has been accepted for inclusion in WVU Graduate Theses, Dissertations, and Problem Reports collection by an authorized administrator of The Research Repository @ WVU. For more information, please contact researchrepository@mail.wvu.edu. 
Productivity Index of Horizontal Gas Well

Abdullah A. Almuraikhi

Thesis submitted to the College of Engineering and Mineral Resources

At West Virginia University

In partial fulfillment of the requirements

for the degree of

Master of Science

In

Petroleum and Natural Gas Engineering

Kashy Aminian, Ph.D., Chair

Sam Ameri, Prof.

Mehrdad Zamirian, Ph.D.

Department of Petroleum and Natural Gas Engineering

Morgantown, West Virginia

2017

Keywords: Productivity index of gas horizontal well

Copyright 2017 Abdullah A. Almuraikhi 


\section{ABSTRACT \\ Productivity Index of Horizontal Gas Well}

Abdullah A. Almuraikhi

One of the most direct techniques to evaluate gas well production capacity is by productivity index (PI). As the application of horizontal wells has significantly increased since 1980s, a number of correlations for predicting the horizontal well PI have been developed by modification of the PI correlations for vertical wells. However, the predicted PI values by different correlations differ significantly. Furthermore, there are no available guidelines for proper application of the various correlations. The objective of this research is to determine the most reliable correlation for horizontal well productivity index in a gas reservoir and identify the key parameters that impact PI of horizontal gas wells.

In order to achieve the objectives, a numerical reservoir model was utilized to determine the productivity index for a horizontal well in a gas reservoir. A parametric study was then conducted to investigate the impact of different reservoir/well parameters including reservoir thickness, lateral length, horizontal permeability, and vertical permeability on PI. The productivity index determined by the simulation model was then compared against the values predicted by different correlations. The results indicate that in all cases the Renard-Dupuy anisotropic correlation will provide the closest value to the model average PI value. Moreover, Kuchuk correlation resulted in the highest value for $\mathrm{PI}$, whereas Babu-Odeh correlation value resulted in the lowest value for $\mathrm{PI}$ in all cases. 


\section{ACKNOWLEDGMENT}

I would like to express my appreciation to my academic/research advisor Dr. Kashy Aminian for his support and guidance during my graduate program. His support, help and professional assistance made me completed my studies and thesis, which concluded in the achievement of M.S degree.

Sincerely thanks to Professor Sam Ameri, Department Chair, for his support and guidance during my studies at West Virginia University. His support and continuous motivation was a perfect asset. I appreciate his enthusiasm to be on my committee.

I would like to extend my sincere thanks to Dr. Mehrdad Zamirian for his support and guidance during my research and for being on the committee.

Many thanks to the professors of the Petroleum and Natural Gas Engineering Department for the knowledge they shared with me. I also would like to acknowledge Saudi Aramco for their financial and consultation support throughout the research.

To my life-time friends, my wife, my son, my daughter, and my siblings, I cannot imagine life without them and I would like to thank them for their continues support, love and effort they have given to me. They will always be my sunshine and I will always love them deep in my heart.

Finally, deepest gratitude and love goes to my parent, who are the greatest parents someone could ever ask for who made me the person I am today. This thesis is dedicated to the love of my life, my family. 


\section{Table of Contents}

ACSTRACT

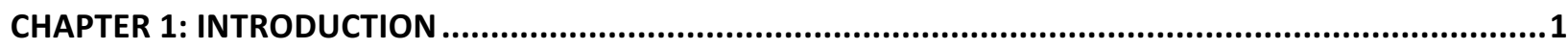

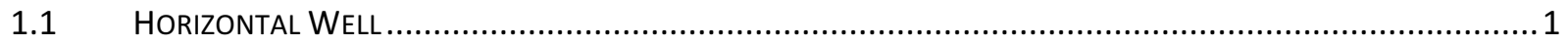

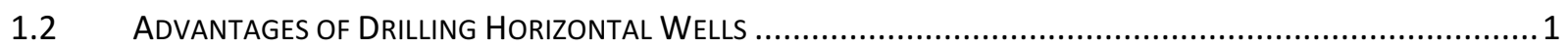

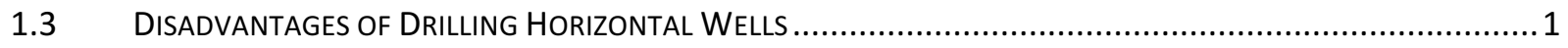

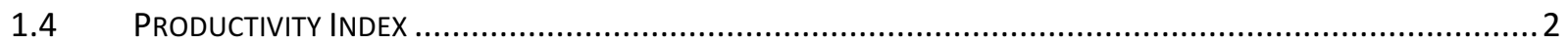

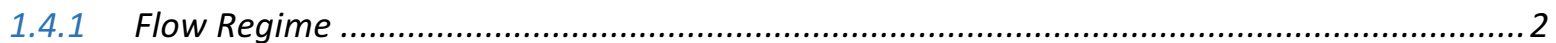

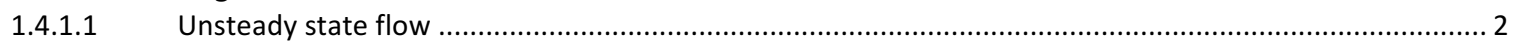

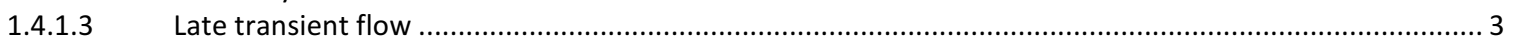

1.4.1.4 Pseudo steady state flow (or Steady state flow) ................................................................................. 3

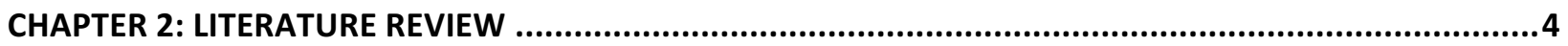

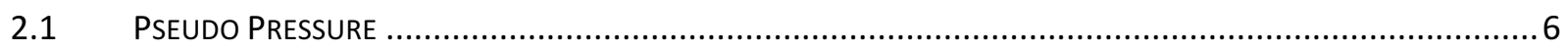

2.1 HORIZONTAL WELL PRODUCTIVITY INDEX CORRELATIONS........................................................ 7

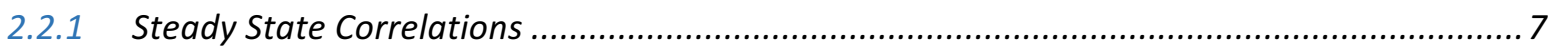

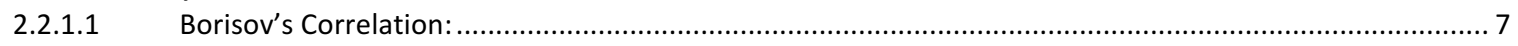

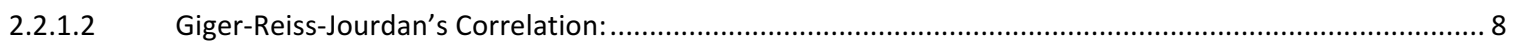

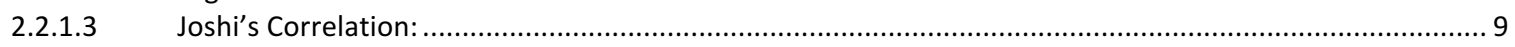

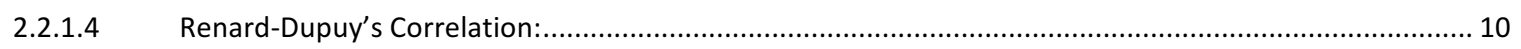

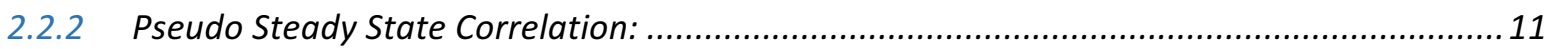

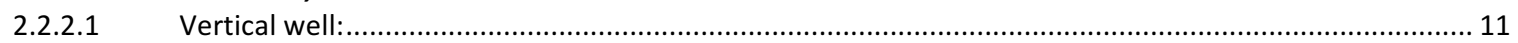

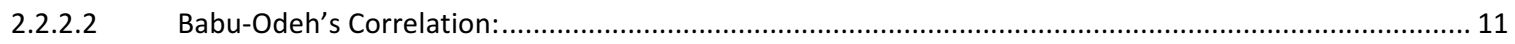

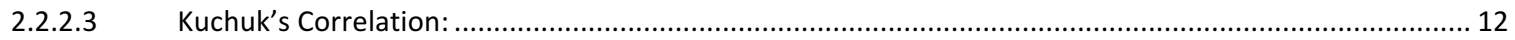

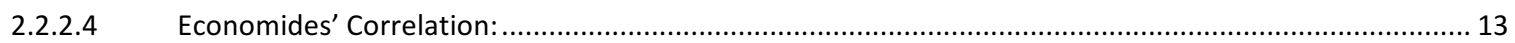

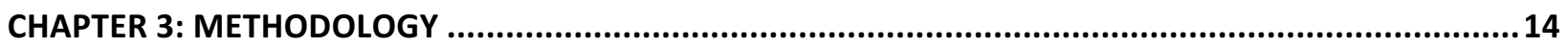

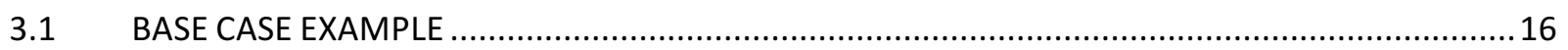

3.2 COMPARISON BETWEEN PI OF VERTICAL AND HORIZONTAL WELL: ......................................21

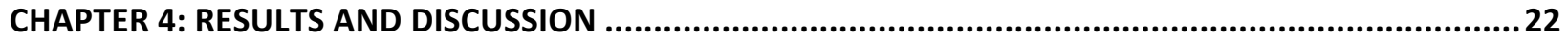

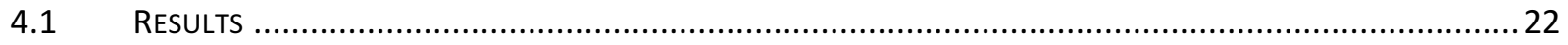

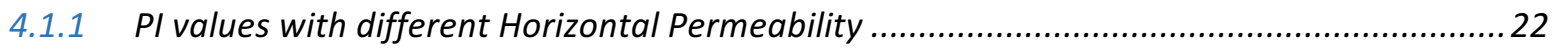

4.1.2 PI values with different Vertical Permeability..................................................................23

4.1.3 PI values with different Reservoir Thickness ...................................................................23

4.1.4 PI values with different Lateral Length .................................................................. 24

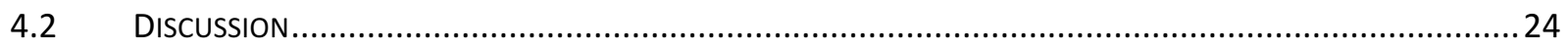

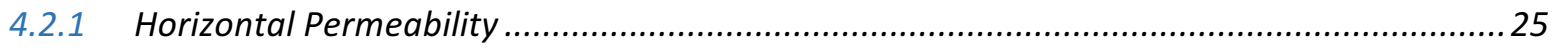

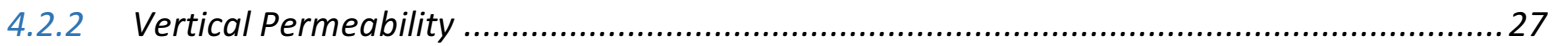

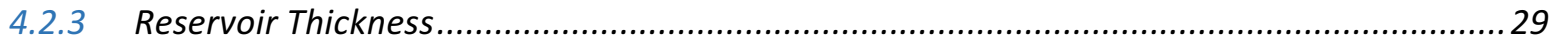

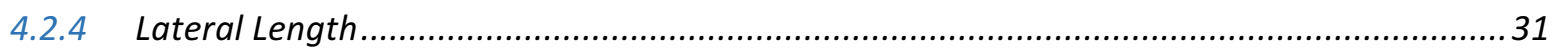

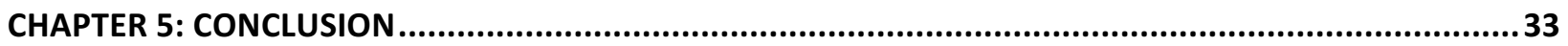

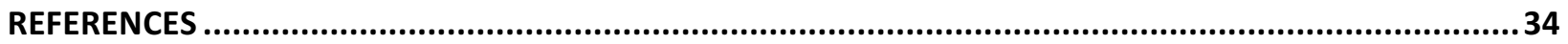




\section{List of Figures}

Figure 1. Productivity Index vs. Time 18

Figure 2. showing all values for PI including CMG 20

Figure 3. PI for anisotropic method with $K_{h}=0.1 \mathrm{mD}$ values

Figure 4. PI for anisotropic method with $K_{h}=0.1 \mathrm{mD}$ values

Figure 5. PI for different anisotropic method with $K_{h}$ values

Figure 6. PI values for anisotropic method with $K v=0.1 \mathrm{mD}$

Figure 7. PI values for anisotropic method with $K v=0.1 \mathrm{mD}$

Figure 8. PI for anisotropic method with different $K v$ values

Figure 9. PI for anisotropic method with $h=10 \mathrm{ft}$. values

Figure 10. PI for anisotropic method with $h=10 \mathrm{ft}$. values

Figure 11. PI for different anisotropic method with Thickness values

Figure 12. Pl for anisotropic method with Lateral length $1000 \mathrm{ft}$. values

Figure 13. PI for anisotropic method with Lateral length $1000 \mathrm{ft}$. values

Figure 14. PI for different anisotropic method with Lateral Length values

Figure 15. CMG launcher

Figure 16. Reservoir simulation setting ___ 37

Figure 17. CMG Builder____ 37

Figure 18. CMG Builder_______ 38

Figure 19. General Property Specification ____ 38

Figure 20. Rock compressibility ___ 39

Figure 21. Imwx PVT Regions________ 39

Figure 22. Rock type ___ 40

Figure 23. $\mathrm{KrVs}$. Sg___ 41

Figure 24. Kr Vs. Sw_ 41

Figure 25. Initial condition ___ 42

Figure 26. Initial condition ___ 43

Figure 27. Well events____ 44

Figure 28. Well events____ 44

Figure 29. Well completion data____ 45

Figure 30. Well completion data___ 45

Figure 31. Top view____ 46

\section{List of Tables}

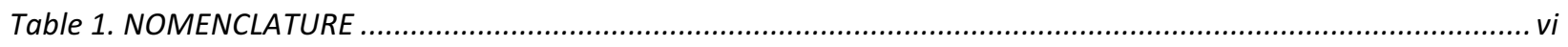

Table 2. Reservoir and Fluid (gas) Properties for the Simulation Model..........................................................15

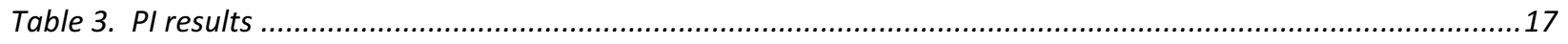

Table 4. PI for all correlations compared with simulator high value ..............................................................19

Table 5. PI for all correlations compared with simulator low value ...........................................................19

Table 6. PI for all correlations compared with simulator average value ............................................................20

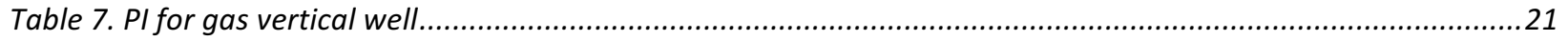

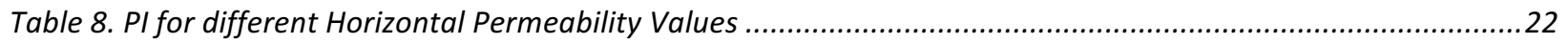

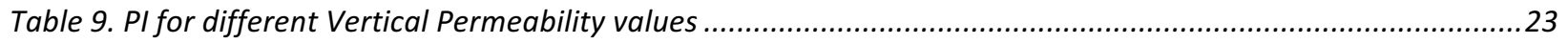

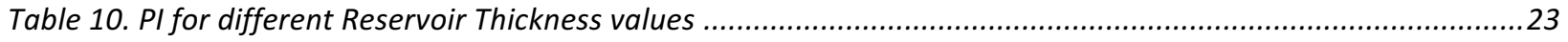

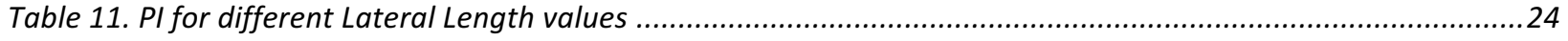




\section{NOMENCLATURE}

\section{Table 1. NOMENCLATURE}

\begin{tabular}{|c|c|}
\hline $\mathbf{J}$ & Productivity index, SCF $/ \mathrm{psi}^{2} / \mathrm{day} / \mathrm{cp}$ \\
\hline $\mathbf{K}$ & Permeability, md \\
\hline $\mathbf{K}_{\mathbf{h}}$ & Horizontal permeability, md k $\mathrm{k}_{\mathrm{v}}$ Vertical permeability, md \\
\hline $\mathbf{K}_{\mathbf{x}}$ & Permeability in $\mathrm{x}$-direction, md \\
\hline $\mathbf{K}_{\mathbf{y}}$ & Permeability in y-direction, md \\
\hline $\mathbf{K}_{\mathbf{z}}$ & Permeability in z-direction, md \\
\hline $\mathbf{K}_{\text {ave }}$ & Average permeability, md \\
\hline $\mathbf{P}_{\mathbf{i}}$ & Initial reservoir pressure, psi \\
\hline $\mathbf{P}_{\mathrm{wf}}$ & Flowing bottom-hole pressure, psi \\
\hline $\mathbf{r}_{\text {eh }}$ & Drainage radius, $\mathrm{ft}$. \\
\hline $\mathbf{r}_{\mathbf{w}}$ & Effective wellbore radius, $\mathrm{ft}$. \\
\hline $\boldsymbol{\mu}_{\mathrm{g}}$ & Gas viscosity, $\mathrm{cp}$ \\
\hline $\mathbf{T}$ & Temperature, ${ }^{\circ} \mathrm{F}$ \\
\hline $\mathbf{Z}$ & Compressibility factor h Formation thickness, ft. \\
\hline $\mathbf{C}_{\mathrm{H}}$ & Shape factor \\
\hline $\mathbf{L}$ & Horizontal well length, ft. \\
\hline $\mathbf{Z}_{\mathrm{w}}$ & Standoff, or distance of well from middle of reservoir, $\mathrm{ft}$. \\
\hline$\varphi$ & Porosity, \% \\
\hline A & Area, $\mathrm{ft}^{2}$ \\
\hline$x_{0}, z_{0}$ & Coordinates measuring the center of well in vertical plane Depth, $\mathrm{ft}$. \\
\hline D & Depth, $\mathrm{ft}$. \\
\hline a & Half major axis of drainage ellipse, $\mathrm{ft}$. \\
\hline $\mathbf{X}$ & Dimensionless drainage configuration parameter \\
\hline $\mathbf{S}_{\mathbf{R}}$ & Skin effect \\
\hline $\mathbf{P}_{\mathrm{wD}}$ & Dimensionless pseudo steady state pressure \\
\hline $\mathbf{S}_{\mathbf{m}}$ & Van Everdingen mechanical skin \\
\hline $\mathbf{X}_{\mathbf{e}}$ & Extent of drainage area in $\mathrm{x}$-direction, $\mathrm{ft}$. \\
\hline $\mathbf{P}_{\mathbf{D}}$ & Dimensionless pressure \\
\hline $\mathbf{S}_{\mathbf{x}}$ & Skin effect \\
\hline $\mathbf{S}_{\mathbf{e}}$ & Eccentricity effect in vertical direction \\
\hline $\mathbf{m}$ & Pseudo pressure, $\mathrm{psi}^{2} / \mathrm{cp}$ \\
\hline
\end{tabular}




\section{CHAPTER 1: INTRODUCTION}

\subsection{Horizontal Well}

Horizontal well is defined as a well that has an access to hydrocarbon reserves at wide range of angles- The interest in horizontal wells initiated in 1980s. Horizontal wells are significantly more productive than vertical wells since it allows a single well to reach multiple points in the reservoir. Also, it reduces the risk of penetrating water in gas or oil exploration.

\subsection{Advantages of Drilling Horizontal Wells}

The advantages of drilling horizontal wells are:

1. To reduce water and gas coning (encroachment).

2. To increased contact with the formation.

3. To increase hydrocarbon production rate since it is exposed to more of the pay zone.

4. To increase production and lower risk.

5. Higher probability to encounter natural fractures which enhances overall recovery.

6. To enable drilling under populated/protected areas.

7. To lower fluid velocities around the wellbore.

\subsection{Disadvantages of Drilling Horizontal Wells}

The disadvantages of drilling horizontal wells are:

1. Higher drilling and completion costs.

2. Higher risk of interfering with other wells.

3. Requires more complicated drilling and completion technologies in especially in thin zones.

4. Hole collapse and cleaning issues.

5. Hole geometry while drilling. 


\subsection{Productivity Index}

The productivity index is measure of potential and performance of the well. PI represents the ability of a reservoir to deliver the fluid to the wellbore. Therefore, the productivity index is defined as the ratio of the flow rate to the pressure drawdown at the midpoint with a unit of (bbl/psi/day) as shown below:

$$
J=\frac{q}{\Delta P}=\frac{q}{\left(p_{r}-p_{w f}\right)}
$$

where,

- $\mathrm{J}=$ Productivity Index, bbl/psi/day

- $\mathrm{q}=$ flowrate at standard conditions, bbl /D

- $P_{r}=$ reservoir pressure, $p s i$

- $P_{\mathrm{wf}}=$ flowing wellhead pressure, $\mathrm{psi}$

\subsubsection{Flow Regime}

During the hydrocarbon production cycle, the producing well goes through three flow periods, flow regimes based on the production time and the boundary conditions. These three periods are:

- Unsteady state flow.

- Late transient flow.

- Pseudo steady state flow (or Steady state flow).

\subsubsection{Unsteady state flow}

Unsteady state flow is the starting life of a well. Also, it is known as an infinite acting that the production of a well has not reached to the boundary of the reservoir. So that the reservoir boundaries have no effect on the well performance. During this period the rate of pressure respect to time depends on both the radius and the time of production as shown below:

$$
\frac{d p}{d t}=f(r, t) \text {, where } r \text { is the radius and } t \text { is the time. }
$$




\subsubsection{Late transient flow}

It is a state between the unsteady state and the pseudo steady state regimes. It occurs when the pressure disturbance caused by the production of a well has reached some of the reservoir boundaries.

\subsubsection{Pseudo steady state flow (or Steady state flow)}

Pseudo steady state is when the production of a well has reached all the reservoir boundaries. During this period the pressure drops at the same constant rate throughout the reservoir.

$$
\frac{\mathrm{dp}}{\mathrm{dt}}=\text { constant rate }
$$

Steady state flow is a special case of pseudo steady state flow when:

$$
\frac{\mathrm{dp}}{\mathrm{dt}}=0
$$

In this flow period the production has no impact on the pressure. The reservoir pressure is sustained by either an aquifer support or a gas cap expansion. 


\section{CHAPTER 2: LITERATURE REVIEW}

Productivity index represents the production capacity of a well. Productivity index is defined as the rate of production per unit pressure drawdown. The constant flow rate of a well is also simulation to evaluate the long-term productivity phenomena of the well. Horizontal wells have proven to be more productive than the vertical well. This is because the horizontal well has an increased drainage area than a vertical well. This indicates that a stimulation vertical well can function more productively than an un-stimulation one (Dankwa et al., 2011).

However, horizontal wells have certain disadvantages over the corresponding vertical wells (Babu et al., 417). For instance, the cost of constructing a horizontal well exceeds about two times the similar vertical well on a reservoir. Therefore, a close analysis should be conducted to consider the performance of horizontal well and its advantages over vertical wells in oil fields.

The first study is under partial completion where the productivity index is investigated based on completion flow rate from reduced production interval of all the system. This thus induces a pressure decrease at wellbore area under vertical wells. In order to study the completion flow rate, various factors are calculated such as pseudo skin, penetration ratios, reservoir drainage system and shape factors. It is noted that a vertical well that is partially completed, it is majorly controlled by the strength. However, vertical permeability, reservoir size, and thickness of the zone affect productivity index at a minimal rate.

The inflow performance of horizontal wells can also be hypothesized to perform calculations on its productivity index. However, when devising the formulas, various restrictions and assumptions were put in place under the geometry. Assumptions were made that the length of the well was longer than the thickness of the formation and shorter than the dimensions of the drainage area. The well is also supposed to be located in the center of the drainage area. Nevertheless, it is assumed that the cross-sectional area of the well covers the whole width

dimension of the reservoir location. This is essential so as to determine the additional pressure that drops since the well is considered non-fracture. 
The inflow performance of a horizontal well is deemed to be of a steady-state of flow. The steady pseudo nature of a well in horizontal position is the difference calculated between the average pressure of the reservoir and the pressure at the wellbore when it approaches a constant numerical value. This is also essential when calculating the inflow of the well to determine productivity index. When this steady-state pressure is kept constant, it enables further calculations involving drawdown pressure which is needed to flow a unit volume in the well per unit time (Goode et al., 319). The study, therefore, involves generation of applicable formulas as well as their application in both wells with a constant-pressure and those with the pressure boundaries.

Subsequent research also includes evaluating pressure-transient for the horizontal wells. The study incorporates various parameters in build-up tests as well as drawdown analysis. Vertical wells differ from horizontal wells under pressure-transient because horizontal wells show partial penetration phenomenon when they are perforated all through the well. Nevertheless, since the wellbore volume of horizontal wells has a typically increased capacity than vertical wells, it enables a greater period for the storage volume in it (Odeh et al.,1989). Calculations are also involved in calculating the down-hole pressure at the wellbore and assisting in examining the productivity index of the well. The interpretation used in the computation also faced significant challenges since there exist numerous boundaries with unknown separation distances among them (Kuchuk et al., 974). Also, the large anisotropy ratio of the well made it difficult to formulate a final interpretation.

Another research to evaluate the productivity of inclined and horizontal wells was carried out in an anisotropic medium. This study is essential because it provides formulas that are relevant in determining how the slant and anisotropy of permeability of the well. For the purpose of determining the effect of inclining the well on pressure, a simulator is used. To design and recommend the type of well to be dug on a reservoir, various factors should be considered such as permeability of the area. For instance, a low permeable reservoir uses the horizontal well to boost the productivity index (Besson et al., 1990). The performances of the slanting well and the 
corresponding horizontal well were evaluated using a geometric pseudo skin factor. Under isotropic reservoirs, drilling a horizontal well has proven to be much more advantageous than the slanting wells. On the contrary, under anisotropic reservoirs, there exists a critical point under the length of the well under which slanting has proven to be more advantageous than horizontal well (Joshi et al., 729).

Other researchers try to evaluate and formulate equations to work out the right productivity index of a horizontal well from the earlier vertical wells. Construction of such wells also depends on the permeability of the reservoir and numerical geometries (Giger et al., 1997). Various models have been generated and argued over the past decades ranging from Borisov to Babu and Odeh models. Therefore, to resolve the issue of emanating models and argumentation of such model formula calculation, obtaining a general productivity index could largely be of help.

The future of petroleum drilling depends on the design and application of well-suited wells. Horizontal wells have proven to be the most efficient drilling method due to its ability to contact a much larger reservoir area (Economides et al., 258). Nevertheless, horizontal wells drilled over the reservoir area come into contact with fractures that assist in draining efficiently. Also, horizontal wells have the ability to minimize water and gas coning behaviors for which vertical wells fail to do so. For this case, the emergence of sound horizontal drilling has been applied widely up to more than 30 wells across the world. For instance, in Colombia, about 20 wells have been constructed (Saavedra et al., 2000). However, the horizontal well faces particular challenges such as they cannot be applied in thick reservoirs, expensive to construct and an area with several petroleum zones will require drilling of numerous horizontal wells.

\subsection{Pseudo Pressure}

Pseudo pressure is considered to be a pseudo property of a gas since it depends on a gas viscosity and compressibility factors, which are properties of the gas. Moreover, pseudo pressure is widely used for mathematical modeling of IPR of gas wells and it gives an accurate pressure. It can be defined as: 


$$
P_{p}=\int_{0}^{p} \frac{2 P}{\mu_{g} Z} d p
$$

However, a spreadsheet program has been developed to estimate pseudo pressure by entering certain parameters such as: gas gravity, base pressure, reservoir temperature, and mole percentage to get the accurate pressure of the reservoir.

\subsection{Horizontal Well Productivity Index Correlations}

There are different correlations available for calculating the productivity index of horizontal gas wells. There are two general categories including Steady-state and pseudo-steady state correlations which will be presented below.

\subsubsection{Steady State Correlations}

There are four major steady state correlations to predict the productivity index of gas horizontal wells. These methods are:

1. Borisov's method.

2. Giger-Reiss-Jourdan method.

3. Joshi's method.

4. Rendard-Dupuy method.

\subsubsection{Borisov's Correlation:}

The prediction of productivity index of horizontal gas well is corrected from the horizontal oil well equation by the compressibility and viscosity difference between oil (slightly compressible) and gas (compressible). Thus, the equation will be: 


$$
J=\frac{0.703 * h * K h * \mu g * z}{T\left(\ln \left(\frac{4 r e h}{L}\right)+\left(\frac{L}{h}\right) \ln \left(\frac{h}{2 \pi r w}\right)\right)}
$$

\subsubsection{Giger-Reiss-Jourdan's Correlation:}

The prediction of productivity index of horizontal gas well is corrected from the horizontal oil well equation by the compressibility and viscosity difference between oil (slightly compressible) and gas (compressible). Thus, the equation will be:

Isotropic reservoir:

$$
J=\frac{0.703 * L * K h * \mu g * z}{T\left(\left(\frac{L}{h}\right) \ln (X)+\ln \left(\frac{h}{2 r w}\right)\right)}
$$

An-isotropic reservoir:

$$
J=\frac{0.703 * K h * \mu g * z}{T\left(\left(\frac{1}{h}\right) \ln (X)+\left(\frac{B^{2}}{L}\right) \ln \left(\frac{h}{2 r w}\right)\right)}
$$

Where,

$$
\begin{gathered}
X=\frac{1+\sqrt{1+\left(\frac{L}{2 r e h}\right)^{2}}}{\frac{L}{(2 r e h)}} \\
B=\sqrt{\frac{K h}{K v}}
\end{gathered}
$$




\subsubsection{Joshi's Correlation:}

The prediction of productivity index of horizontal gas well is corrected from the horizontal oil well equation by the compressibility and viscosity difference between oil (slightly compressible) and gas (compressible). Thus, the equation will be:

Isotropic reservoir:

$$
J=\frac{0.703 * h * K h * \mu g * z}{T\left(\ln (R)+\left(\frac{h}{L}\right) \ln \left(\frac{h}{2 r w}\right)\right)}
$$

Anisotropic reservoir:

$$
J=\frac{0.703 * h * K h * \mu g * z}{T\left(\ln (R)+\left(\frac{B^{2} h}{L}\right) \ln \left(\frac{h}{2 r w}\right)\right)}
$$

Where,

$$
\begin{gathered}
B=\sqrt{\frac{K h}{K v}} \\
a=\frac{L}{2}\left(0.5+\sqrt{0.25+\left(\frac{2 r e h}{L}\right)^{4}}\right)^{0.5} \\
R=\frac{a+\sqrt{a^{2}+\left(\frac{L}{2}\right)^{2}}}{\frac{L}{(2)}}
\end{gathered}
$$




\subsubsection{Renard-Dupuy's Correlation:}

The prediction of productivity index of horizontal gas well is corrected from the horizontal oil well equation by the compressibility and viscosity difference between oil (slightly compressible) and gas (compressible). Thus, the equation will be:

Isotropic reservoir:

$$
J=\frac{0.703 * h * K h * \mu g * z}{T\left(\cosh ^{-1}\left(\frac{2 a}{L}\right)+\left(\frac{h}{L}\right) \ln \left(\frac{h}{2 \pi r w}\right)\right)}
$$

An-isotropic reservoir:

$$
J=\frac{0.703 * h * K h * \mu g * z}{T\left(\cosh ^{-1}\left(\frac{2 a}{L}\right)+\left(\frac{B h}{L}\right) \ln \left(\frac{h}{2 \pi r^{\prime} w}\right)\right)}
$$

Where,

$$
\begin{gathered}
a=\frac{L}{2}\left(0.5+\sqrt{0.25+\left(\frac{2 r e h}{L}\right)^{4}}\right)^{0.5} \\
B=\sqrt{\frac{K h}{K v}} \\
r^{\prime} w=\frac{(1+B) r w}{2 B}
\end{gathered}
$$




\subsubsection{Pseudo Steady State Correlation:}

There are four major pseudo steady state equations to measure the productivity index of horizontal gas wells. For comparison purposes, all of these horizontal models are compared to productivity index that been calculated from a simulator model (CMG). These methods are:

1. Vertical well.

2. Babu-Odeh method.

3. Kuchuk method.

4. Economides method.

\subsubsection{Vertical well:}

The prediction of the productivity index of vertical gas wells is corrected from the vertical oil wells' equation to account for the compressibility and viscosity differences between oil (slightly compressible) and gas (compressible). Thus, the equation will be:

$$
J=\frac{0.703 * k * h * \mu g * z}{T\left[\ln \frac{r e}{r w}-0.75+s\right]}
$$

\subsubsection{Babu-Odeh's Correlation:}

The objective of this method is to provide an easy way to calculate PI of a gas horizontal well. The productivity index of horizontal gas well is corrected from the horizontal oil well equation by the compressibility and viscosity difference between oil (slightly compressible) and gas (compressible). Thus, the equation will be:

$$
J=\frac{0.703 * b * \sqrt{K x K z} * \mu g * z}{T\left(\ln \left(C H * A^{\frac{1}{2}} * r w\right)-0.75+S R\right)}
$$


Where: $S R$ is a function that depends strongly on the well length $L$. $S R=0$ when $L=b$ (the fully penetrating case).

$$
\begin{aligned}
\ln (C H)= & 6.28 *\left(\frac{a}{h}\right) \sqrt{\frac{K z}{K x}} *\left(\left(\frac{1}{3}\right)-\frac{X o}{a}+\left(\frac{X o}{a}\right)^{2}\right)-\ln \left(\sin \frac{180 z o}{h}\right)-0.5 \ln \left(\left(\frac{a}{h}\right) \sqrt{\frac{K z}{K x}}\right) \\
- & 1.088
\end{aligned}
$$

xo and zo are coordinates that measure the center of the well in the vertical plane, $(\mathrm{a})$ is the dimension of the drainage area.

\subsubsection{Kuchuk's Correlation:}

The productivity equation suggested by Kuchuk used an approximate infinite conductivity solution. The productivity index of horizontal gas well is corrected from the horizontal oil well equation by the compressibility and viscosity difference between oil (slightly compressible) and gas (compressible). Thus, the equation will be:

$$
\begin{gathered}
J=\frac{0.703 * K H * h * \mu g * z}{T\left(P w D+S M^{*}\right)} \\
K_{h}=\sqrt{K x * K y} \\
\left.P w D=\frac{h}{2 L \frac{1}{2}} \sqrt{\frac{K x}{K z}}\left(\ln \frac{8 h}{\pi * r^{\prime} w} \cot \left(\frac{\pi * Z w}{2 h}\right)\right)+\frac{Z w-h}{L \frac{1}{2}} \sqrt{\frac{K x}{K z}}\right) \\
S m=\left(\frac{2 \pi * L \frac{1}{2} \sqrt{K y * K z}}{\mu * q}\right) * \Delta P S
\end{gathered}
$$




$$
S M^{*}=\frac{h}{2 L \frac{1}{2}} \sqrt{\frac{K x}{K z}} * S m
$$

Since the skin is zero, both $\mathrm{Sm}$ and $\mathrm{Sm} *$ should be negligible.

\subsubsection{Economides' Correlation:}

Economides suggested a methodology of calculating well performance of arbitrarily oriented, single or multiple well configurations, based on evaluated analytical solutions. This approach is general, readily reproduce well-known analytical solutions, and can be used for transient, mixed, and no flow boundary conditions. However, the productivity index of horizontal gas well is corrected from the horizontal oil well equation by the compressibility and viscosity difference between oil (slightly compressible) and gas (compressible). Thus, the equation will be:

$$
J=\frac{0.703 * \text { Kave } * X e * \mu * Z}{T\left(P D+\frac{X e}{2 \pi L} \sum S\right)}
$$

Where,

$$
\begin{gathered}
P D=\frac{X e C H}{4 \pi h}+\frac{X e}{2 \pi L} S x \\
S x=\ln \left(\frac{h}{2 \pi r w}\right)-\frac{h}{6 L}+S e \\
S e=\frac{h}{L}\left(\left(\frac{2 * Z w}{h}\right)-\frac{1}{2}\left(\frac{2 * Z w}{h}\right)^{2}-\frac{1}{2}\right)-\ln \left(\sin \left(\frac{\pi * Z w}{h}\right)\right)
\end{gathered}
$$




\section{CHAPTER 3: METHODOLOGY}

The objective of this research is to evaluate different productivity index correlations for a gas horizontal well using different reservoir/well parameters. To achieve this goal, the following steps were considered:

1. A numerical reservoir simulator (CMG) was utilized to build a gas reservoir model with one horizontal well. The reservoir properties used in developing the simulation model are listed in Table 2.

2. After running simulator and taking the results (gas rate $\&$ reservoir pressure), the pressure can be corrected to pseudopressure (Pp). Subsequently, the productivity index was calculated.

3. The calculated PI was compared to estimate values from both steady state and pseudosteady state correlations to evaluate which correlation provides the most reliable results.

4. The PI for vertical well was calculated using pseudosteady state correlation to compare it with the horizontal PI in order to illustrate the advantage of horizontal well.

The following example illustrates the methodology in detail for the base case. 
Table 2. Reservoir and Fluid (gas) Properties for the Simulation Model

\begin{tabular}{|c|c|c|}
\hline Parameters & Base Case & Range \\
\hline Formation thickness $(\mathrm{h}), \mathrm{ft}$. & 30 & $10-50$ \\
\hline Horizontal permeability $\left(\mathrm{k}_{\mathrm{h}}\right)$, md. & 0.1 & $0.1-0.5$ \\
\hline Gas Viscosity (u), cp. & 0.019 & 0.019 \\
\hline Depth (d), ft. & 6000 & $6000-7000$ \\
\hline Length of horizontal well (L), ft. & 2000 & $1000-2500$ \\
\hline Wellbore radius $\left(\mathrm{r}_{\mathrm{w}}\right), \mathrm{ft}$. & 0.5 & 0.5 \\
\hline Vertical Permeability $\left(\mathrm{k}_{\mathrm{v}}\right)$, md. & 0.01 & $0.01-0.5$ \\
\hline Temperature $(\mathrm{T}),{ }^{\circ} \mathrm{F}$. & 120 & 120 \\
\hline Reservoir radius $\left(\mathrm{r}_{\mathrm{e}}\right), \mathrm{ft}$. & 2000 & $2000-4000$ \\
\hline Skin factor (s). & 0 & 0 \\
\hline Initial Reservoir pressure (P), psi. & 3000 & 3000 \\
\hline Flowing bottom-hole pressure $\left(\mathrm{p}_{\mathrm{wf}}\right)$, psi. & 500 & 500 \\
\hline Drainage Area $(\mathrm{a} \times \mathrm{b}), \mathrm{ft}^{2}$. & $2000-4000$ & $2000-4000$ \\
\hline Center of the well in the vertical plane $\left(\mathrm{Z}_{\mathrm{o}}\right)$, $\mathrm{ft}$. & mid-point & mid-point \\
\hline Porosity. & 10 & 10 \\
\hline$S_{\text {wi. }}$ & 0.25 & 0.25 \\
\hline Rock Compressibility. & $3.003 \mathrm{E}-3$ & $3.003 \mathrm{E}-3$ \\
\hline
\end{tabular}




\subsection{BASE CASE EXAMPLE}

The simulation run results (time, flow rate, pressure...) for a constant flowing bottomhole pressure were imported to an excel sheet. Then, the reservoir pressures values were converted to pseudopressure (Pp) by using an available Pseudo Excel Sheet. The productivity index was then calculated for over a four-year period of production as shown in the Table 3. Subsequently, a plot was created to obtain the high, low, and the average values of PI for a horizontal gas well as shown in the Figure 1. Finally, PI values were estimated from both steady state and pseudosteady state correlations using the same reservoir parameters as those used in the simulation model and summarized in Tables 4, 5 and 6. Figure 2 compares the PI values from the simulation and various correlations.

This processes were repeated using different parameters to come up with the best correlation that matches the model. 
Table 3. PI results

\begin{tabular}{|c|c|c|c|c|c|}
\hline TIME & DATE & Gas Rate SC - Monthly & Reservoir Pressure & $\mathrm{Pp}$ & $\mathrm{Pl}$ using $\mathrm{Pp}$ \\
\hline (day) & & (ft3/day) & (psi) & $p s i^{\wedge} 2 / c p$ & $\mathrm{SCF} / \mathrm{psi}^{\wedge} 2 / \mathrm{day} / \mathrm{cp}$ \\
\hline 31 & $2 / 1 / 16$ & 5922739.5 & 2954 & 613486473.6 & 0.00999 \\
\hline 60 & $3 / 1 / 16$ & 3783097.5 & 2927 & 603536343.5 & 0.00649 \\
\hline 91 & $4 / 1 / 16$ & 3215070 & 2902 & 594371786.2 & 0.00560 \\
\hline 121 & $5 / 1 / 16$ & 2834788.25 & 2880 & 586346078.7 & 0.00501 \\
\hline 152 & $6 / 1 / 16$ & 2566613.75 & 2860 & 579082119.7 & 0.00459 \\
\hline 182 & $7 / 1 / 16$ & 2370173.75 & 2842 & 572570998.6 & 0.00429 \\
\hline 213 & $8 / 1 / 16$ & 2215913.25 & 2824 & 566085168 & 0.00406 \\
\hline 244 & $9 / 1 / 16$ & 2091319.75 & 2807 & 559983092.4 & 0.00388 \\
\hline 274 & $10 / 1 / 16$ & 1990643.25 & 2792 & 554617969.5 & 0.00373 \\
\hline 305 & $11 / 1 / 16$ & 1904755.625 & 2776 & 548915026.2 & 0.00360 \\
\hline 335 & $12 / 1 / 16$ & 1832061.875 & 2761 & 543587272.3 & 0.00350 \\
\hline 366 & $1 / 1 / 17$ & 1768206.5 & 2747 & 538631198.7 & 0.00341 \\
\hline 397 & $2 / 1 / 17$ & 1711401.25 & 2733 & 533691164.7 & 0.00333 \\
\hline 425 & $3 / 1 / 17$ & 1663904 & 2720 & 529118447.5 & 0.00327 \\
\hline 456 & $4 / 1 / 17$ & 1619377.5 & 2706 & 524209654.8 & 0.00321 \\
\hline 486 & $5 / 1 / 17$ & 1578999.5 & 2693 & 519666135.7 & 0.00316 \\
\hline 517 & $6 / 1 / 17$ & 1541607.25 & 2680 & 515136809.1 & 0.00312 \\
\hline 547 & $7 / 1 / 17$ & 1507746.125 & 2668 & 510968564.5 & 0.00307 \\
\hline 578 & $8 / 1 / 17$ & 1476058.875 & 2655 & 506466776.2 & 0.00304 \\
\hline 609 & $9 / 1 / 17$ & 1446445.375 & 2643 & 502324100.2 & 0.00300 \\
\hline 639 & $10 / 1 / 17$ & 1419392 & 2631 & 498193802.7 & 0.00297 \\
\hline 670 & $11 / 1 / 17$ & 1393701.125 & 2619 & 494075952.1 & 0.00294 \\
\hline 700 & $12 / 1 / 17$ & 1369860.25 & 2608 & 490312248.4 & 0.00292 \\
\hline 731 & $1 / 1 / 18$ & 1347010.125 & 2596 & 486218445.4 & 0.00289 \\
\hline 762 & $2 / 1 / 18$ & 1325196.375 & 2584 & 482137288.5 & 0.00287 \\
\hline 790 & $3 / 1 / 18$ & 1305810.25 & 2574 & 478746033.9 & 0.00285 \\
\hline 821 & $4 / 1 / 18$ & 1286453.625 & 2563 & 475025898.9 & 0.00283 \\
\hline 851 & $5 / 1 / 18$ & 1267946.625 & 2552 & 471316547.6 & 0.00281 \\
\hline 882 & $6 / 1 / 18$ & 1249899.375 & 2541 & 467618032.4 & 0.00280 \\
\hline 912 & $7 / 1 / 18$ & 1232810.625 & 2531 & 464265193.2 & 0.00278 \\
\hline 943 & $8 / 1 / 18$ & 1216095 & 2520 & 460587510.6 & 0.00276 \\
\hline 974 & $9 / 1 / 18$ & 1199859.625 & 2509 & 456920816.3 & 0.00275 \\
\hline 1004 & $10 / 1 / 18$ & 1184512 & 2499 & 453597037.1 & 0.00273 \\
\hline 1035 & $11 / 1 / 18$ & 1169424.5 & 2489 & 450282421.5 & 0.00272 \\
\hline 1065 & $12 / 1 / 18$ & 1155029.375 & 2479 & 446977008.6 & 0.00271 \\
\hline 1096 & $1 / 1 / 19$ & 1140843.375 & 2468 & 443351730.2 & 0.00270 \\
\hline 1127 & $2 / 1 / 19$ & 1126953.25 & 2458 & 440065770.3 & 0.00269 \\
\hline 1155 & $3 / 1 / 19$ & 1114331.375 & 2449 & 437116377.1 & 0.00267 \\
\hline 1186 & $4 / 1 / 19$ & 1101456.5 & 2439 & 433848165.7 & 0.00266 \\
\hline 1216 & $5 / 1 / 19$ & 1088921.625 & 2430 & 430914809.4 & 0.00265 \\
\hline 1247 & $6 / 1 / 19$ & 1076471.75 & 2420 & 427664487 & 0.00264 \\
\hline 1277 & $7 / 1 / 19$ & 1064516.25 & 2411 & 424747294 & 0.00263 \\
\hline 1308 & $8 / 1 / 19$ & 1052622.5 & 2401 & 421515000.9 & 0.00262 \\
\hline 1339 & $9 / 1 / 19$ & 1040945.563 & 2392 & 418614097.2 & 0.00261 \\
\hline
\end{tabular}




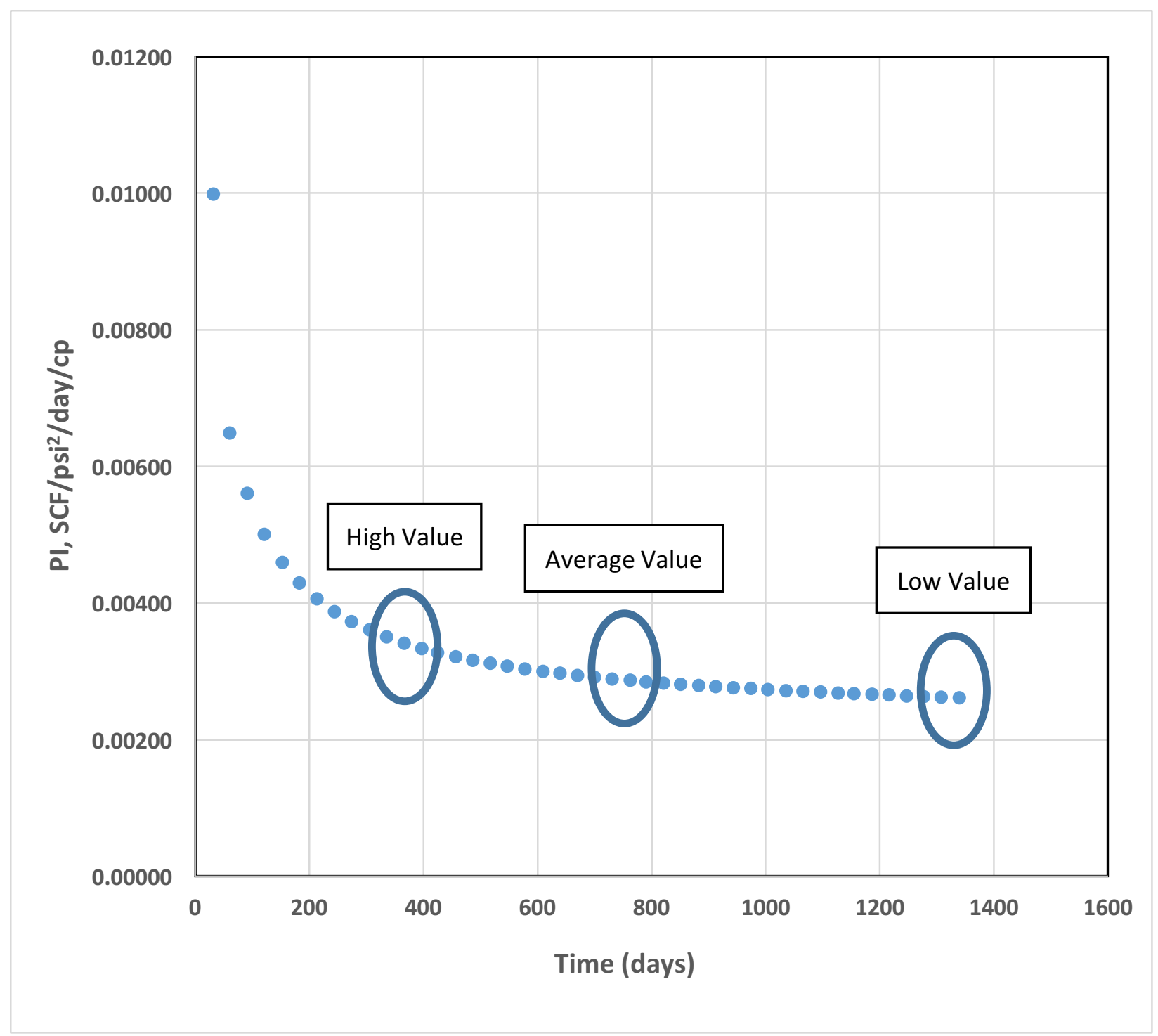

Figure 1. Productivity Index vs. Time 
Table 4. PI for all correlations compared with simulator high value

\begin{tabular}{|c|c|c|}
\hline \multicolumn{2}{|c|}{ Best Correlation with Sim high value } \\
\hline Correlation & Lateral Length, ft. & PI, SCF/psi ${ }^{2} /$ day/cp \\
\hline Sim using Pp :High Value & 2000 & 0.00360 \\
\hline Borisov & 2000 & 0.00304 \\
\hline Renard-Dupuy Isotropic & 2000 & 0.00300 \\
\hline Joshi Isotropic & 2000 & 0.00299 \\
\hline Renard-Dupuy An-Isotropic & 2000 & 0.00281 \\
\hline Giger-Reiss-Jourdan Isotropic & 2000 & 0.00280 \\
\hline Joshi An-Isotropic & 2000 & 0.00217 \\
\hline Giger-Reiss-Jourdan An-Isotropic & 2000 & 0.00207 \\
\hline Babu-Odeh & 2000 & 0.00181 \\
\hline Economides & 2000 & 0.01136 \\
\hline Kuchuk & 2000 & 0.01420 \\
\hline
\end{tabular}

Table 5. PI for all correlations compared with simulator low value

\begin{tabular}{|c|c|c|}
\hline \multicolumn{2}{|c|}{ Best Correlation with Sim Low value } \\
\hline Correlation & Lateral Length, ft. & PI, SCF/psi ${ }^{2} /$ day/cp \\
\hline Sim using Pp :Low Value & 2000 & 0.00261 \\
\hline Giger-Reiss-Jourdan Isotropic & 2000 & 0.00280 \\
\hline Renard-Dupuy An-Isotropic & 2000 & 0.00281 \\
\hline Joshi Isotropic & 2000 & 0.00299 \\
\hline Renard-Dupuy Isotropic & 2000 & 0.00300 \\
\hline Borisov & 2000 & 0.00304 \\
\hline Joshi An-Isotropic & 2000 & 0.00217 \\
\hline Giger-Reiss-Jourdan An-Isotropic & 2000 & 0.00207 \\
\hline Babu-Odeh & 2000 & 0.00181 \\
\hline Kuchuk & 2000 & 0.01420 \\
\hline Economides & 2000 & 0.01136 \\
\hline
\end{tabular}


Table 6. PI for all correlations compared with simulator average value

\begin{tabular}{|c|c|c|}
\hline \multicolumn{2}{|c|}{ Best Corrolation with Sim Avg. value } \\
\hline Correlation & Lateral Length, ft. & PI, SCF/psi ${ }^{2} / \mathrm{day} / \mathrm{cp}$ \\
\hline Sim using Pp :Avg. Value & 2000 & 0.003105 \\
\hline Borisov & 2000 & 0.003045 \\
\hline Renard-Dupuy Isotropic & 2000 & 0.002999 \\
\hline Joshi Isotropic & 2000 & 0.002990 \\
\hline Renard-Dupuy An-Isotropic & 2000 & 0.002807 \\
\hline Giger-Reiss-Jourdan Isotropic & 2000 & 0.002802 \\
\hline Joshi An-Isotropic & 2000 & 0.002170 \\
\hline Giger-Reiss-Jourdan An-Isotropic & 2000 & 0.002070 \\
\hline Babu-Odeh & 2000 & 0.001813 \\
\hline Economides & 2000 & 0.011356 \\
\hline Kuchuk & 2000 & 0.014196 \\
\hline
\end{tabular}

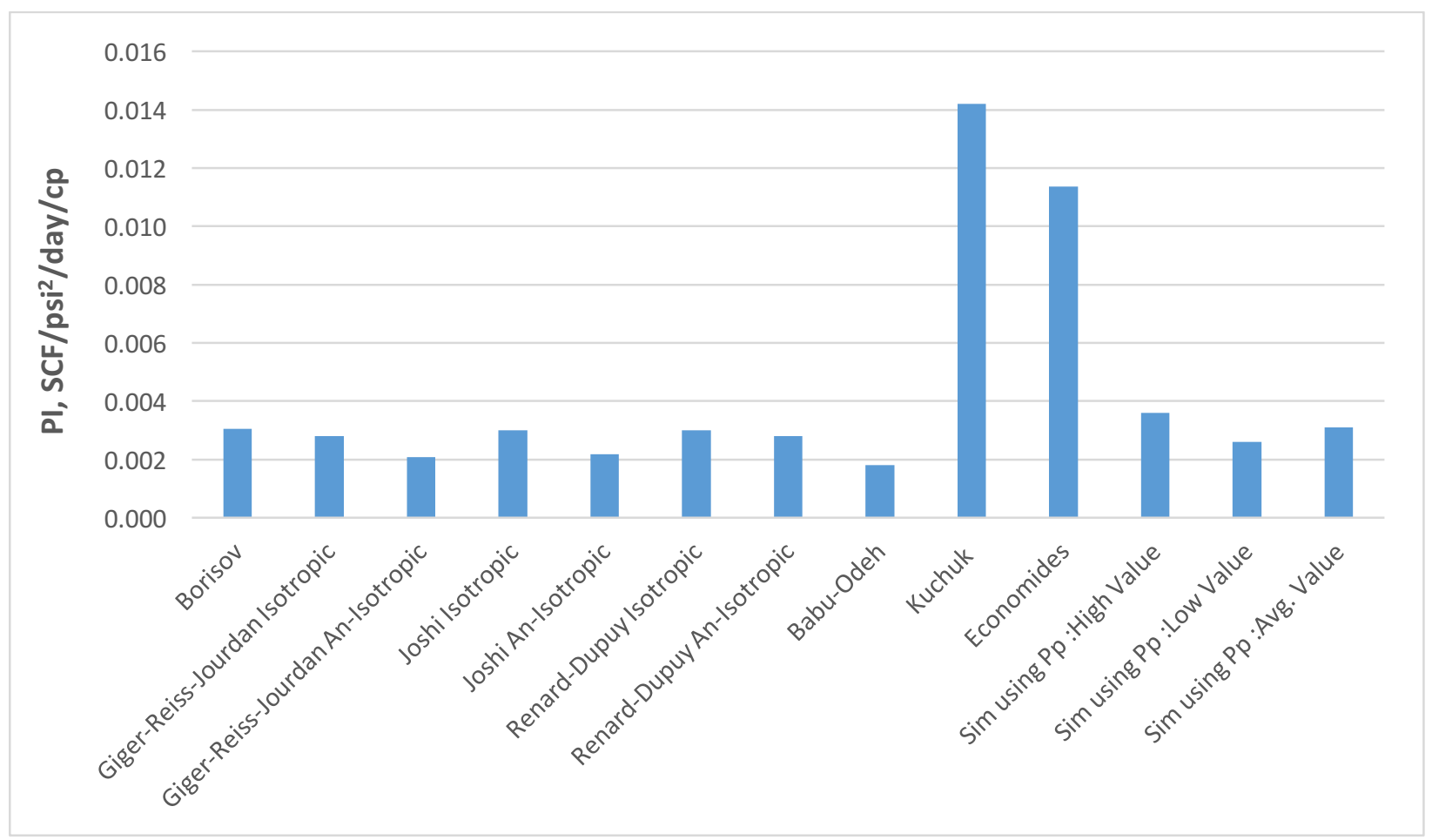

Figure 2. showing all values for PI including CMG 


\subsection{Comparison between PI of vertical and horizontal well:}

The PI value of the vertical well is illustrated in Table 7 (5.22071E-06), which is significantly lower than the PI average value calculated from the model as shown in table 6 (3.105E-03). This comparison was performed to indicate that the PI value for horizontal well is much higher than the vertical.

Table 7. PI for gas vertical well

\begin{tabular}{|c|c|}
\hline \multicolumn{2}{|c|}{ Vertical well } \\
\hline \multicolumn{2}{|c|}{ Base Ccase } \\
\hline Parameters & $\mathrm{PI}, \mathrm{SCF} / \mathrm{psi}^{\wedge} 2 /$ day/cp \\
\hline $\mathrm{h}, \mathrm{ft}$. & 30 \\
\hline $\mathrm{K}_{\mathrm{h}}, \mathrm{md}$ & 0.1 \\
\hline z factor & 0.8284 \\
\hline Temperature, $\mathrm{F}$ & 120 \\
\hline specific Gravity & 0.6 \\
\hline Viscosity, cp & 0.01925 \\
\hline $\mathrm{R}_{\mathrm{e}}, \mathrm{ft}$. & 1595.8 \\
\hline $\mathrm{R}_{\mathrm{w}}, \mathrm{ft}$. & 0.5 \\
\hline $\mathrm{S}$ & 0 \\
\hline $\mathrm{J}$ & $5.22071 \mathrm{E}-06$ \\
\hline
\end{tabular}




\section{CHAPTER 4: RESULTS AND DISCUSSION}

\subsection{Results}

After conducting multiple simulation runs for different reservoir scenarios (Horizontal permeability, Vertical permeability, reservoir thickness and lateral length), the productivity index values were calculated after converting the reservoir pressure to a pseudopressure over a fouryear period of production. Then, a productivity index plots were generated to obtain the high, low and average values from the stabilized zone as shown in Figure 1. Moreover, the PI values from both the steady state and pseudosteady state correlations were calculated using the same reservoir parameters as those used in the simulation model, and were compared with the average PI values that were obtained from the simulator. Finally, the correlation values were arranged per the nearest value of the simulator.

\subsubsection{PI values with different Horizontal Permeability}

Table-8 displays the PI results for different horizontal permeability using base case parameters.

\section{Table 8. PI for different Horizontal Permeability Values}

\begin{tabular}{|c|c|c|c|c|c|}
\hline & \multicolumn{5}{|c|}{$\mathrm{PI}$, SCF/psi^2/day/cp } \\
\hline Correlation & $\mathrm{K}_{\mathrm{h}}=0.1 \mathrm{md}$ & $\mathrm{K}_{\mathrm{h}}=0.2 \mathrm{md}$ & $\mathrm{K}_{\mathrm{h}}=0.3 \mathrm{md}$ & $\begin{array}{c}\mathrm{K}_{\mathrm{h}}=0.4 \\
\mathrm{md}\end{array}$ & $\mathrm{K}_{\mathrm{h}}=0.5 \mathrm{md}$ \\
\hline Model Average Value & 0.003105 & 0.00691 & 0.01036 & 0.013815 & 0.017265 \\
\hline Borisov & 0.003045 & 0.006089 & 0.009134 & 0.012178 & 0.015223 \\
\hline Renard-Dupuy Isotropic & 0.002999 & 0.005997 & 0.008996 & 0.011994 & 0.014993 \\
\hline Joshi Isotropic & 0.002990 & 0.005979 & 0.008969 & 0.011959 & 0.014948 \\
\hline Renard-Dupuy An-Isotropic & 0.002807 & 0.005615 & 0.008422 & 0.011229 & 0.014036 \\
\hline Giger-Reiss-Jourdan Isotropic & 0.002802 & 0.005604 & 0.008406 & 0.011208 & 0.014010 \\
\hline Joshi An-Isotropic & 0.002170 & 0.004341 & 0.006511 & 0.008681 & 0.010852 \\
\hline Giger-Reiss-Jourdan An-Isotropic & 0.002070 & 0.004139 & 0.006209 & 0.008279 & 0.010348 \\
\hline Babu-Odeh & 0.001813 & 0.003627 & 0.005440 & 0.007254 & 0.009067 \\
\hline Economides & 0.011356 & 0.022713 & 0.034069 & 0.045425 & 0.056781 \\
\hline Kuchuk & 0.014196 & 0.028392 & 0.042588 & 0.056784 & 0.070980 \\
\hline
\end{tabular}




\subsubsection{PI values with different Vertical Permeability}

Table-9 displays the PI results for different vertical permeability using base case parameters.

Table 9. PI for different Vertical Permeability values

\begin{tabular}{|c|c|c|c|}
\multirow{2}{*}{ Correlation } & \multicolumn{4}{c|}{$\mathrm{PI}$ SCF/psi^2/day/cp } \\
\cline { 2 - 4 } & $\mathrm{K}_{\mathrm{v}}=0.01 \mathrm{md}$ & $\mathrm{K}_{\mathrm{v}}=0.02 \mathrm{md}$ & $\mathrm{K}_{\mathrm{v}}=0.033 \mathrm{md}$ \\
\hline Model Average Value & 0.003105 & 0.00327 & 0.0033 \\
\hline Renard-Dupuy Isotropic & 0.002999 & 0.002999 & 0.002999 \\
\hline Joshi Isotropic & 0.002990 & 0.002990 & 0.002990 \\
\hline Renard-Dupuy An-Isotropic & 0.002807 & 0.002885 & 0.002929 \\
\hline Giger-Reiss-Jourdan Isotropic & 0.002802 & 0.002802 & 0.002802 \\
\hline Joshi An-Isotropic & 0.002170 & 0.002560 & 0.002755 \\
\hline Giger-Reiss-Jourdan An-Isotropic & 0.002070 & 0.002421 & 0.002598 \\
\hline Babu-Odeh & 0.001813 & 0.001866 & 0.001894 \\
\hline Kuchuk & 0.014196 & 0.020353 & 0.011163 \\
\hline Economides & 0.016154 & 0.020382 & 0.026565 \\
\hline
\end{tabular}

\subsubsection{PI values with different Reservoir Thickness}

Table-10 displays the PI results for different reservoir thickness using base case parameters.

Table 10. PI for different Reservoir Thickness values

\begin{tabular}{|c|c|c|c|}
\hline \multirow{2}{*}{ Correlation } & \multicolumn{3}{c|}{$\mathrm{PI}, \mathrm{SCF} / \mathrm{psi} 2 /$ day/cp } \\
\hline Model Average Value & $\mathrm{h}=30 \mathrm{ft}$ & $\mathrm{h}=10 \mathrm{ft}$ & $\mathrm{h}=50 \mathrm{ft}$ \\
\hline Borisov & 0.003105 & 0.00117 & 0.0045 \\
\hline Renard-Dupuy Isotropic & 0.003045 & 0.001039 & 0.004507 \\
\hline Joshi Isotropic & 0.002999 & 0.001031 & 0.004261 \\
\hline Renard-Dupuy An-Isotropic & 0.002990 & 0.001030 & 0.004798 \\
\hline Giger-Reiss-Jourdan Isotropic & 0.002807 & 0.001017 & 0.004821 \\
\hline Joshi An-Isotropic & 0.002802 & 0.000963 & 0.004928 \\
\hline Giger-Reiss-Jourdan An-Isotropic & 0.002170 & 0.000947 & 0.003371 \\
\hline Babu-Odeh & 0.002070 & 0.000890 & 0.002828 \\
\hline Economides & 0.011356 & 0.003903 & 0.011356 \\
\hline Kuchuk & 0.014196 & 0.009248 & 0.014196 \\
\hline
\end{tabular}




\subsubsection{PI values with different Lateral Length}

Table-11 displays the PI results for different lateral lengths using base case parameters.

Table 11. PI for different Lateral Length values

\begin{tabular}{|c|c|c|c|c|}
\hline \multirow{2}{*}{ Correlation } & \multicolumn{4}{c|}{$\mathrm{PI}$, SCF/psi^2/day/cp } \\
\cline { 2 - 5 } & $\mathrm{L}=1000 \mathrm{ft}$ & $\mathrm{L}=1500 \mathrm{ft}$ & $\mathrm{L}=2000 \mathrm{ft}$ & $\mathrm{L}=2500 \mathrm{ft}$ \\
\hline Model Average Value & 0.00173 & 0.00242 & 0.003105 & 0.00409 \\
\hline Borisov & 0.00172 & 0.00243 & 0.003045 & 0.00377 \\
\hline Renard-Dupuy Isotropic & 0.00184 & 0.00240 & 0.002999 & 0.00369 \\
\hline Joshi Isotropic & 0.00186 & 0.00240 & 0.002990 & 0.00367 \\
\hline Giger-Reiss-Jourdan Isotropic & 0.00187 & 0.00232 & 0.002807 & 0.00345 \\
\hline Renard-Dupuy An-Isotropic & 0.00189 & 0.00224 & 0.002802 & 0.00329 \\
\hline Joshi An-Isotropic & 0.00127 & 0.00171 & 0.002170 & 0.00268 \\
\hline Giger-Reiss-Jourdan An-Isotropic & 0.00125 & 0.00167 & 0.002070 & 0.00247 \\
\hline Babu-Odeh & 0.00122 & 0.00149 & 0.001813 & 0.00219 \\
\hline Economides & 0.00638 & 0.00820 & 0.011356 & 0.01449 \\
\hline Kuchuk & 0.00716 & 0.01068 & 0.014196 & 0.01771 \\
\hline
\end{tabular}

\subsection{Discussion}

Initially, correlations for isotropic reservoirs were included in calculation of the PI for both steady state and pseudo steady state, to investigate if there was any significant differences between the outcomes of the isotropic and anisotropic correlations as shown on the result section. Since the reservoir model was built based on an anisotropic reservoir, the isotropic correlations were excluded to have more accurate comparison. Furthermore, the best correlation will be determined after evaluating the different scenarios which include different horizontal permeability, vertical permeability, reservoir thickness and lateral lengths. 


\subsubsection{Horizontal Permeability}

PI values obtained from different correlations using horizontal permeability range from 0.1 to 0.5 md, along with the average PI values obtained from the model. Figure-3 \& 4 demonstrates the model average $\mathrm{PI}$ value and the $\mathrm{PI}$ values from the other correlations using a horizontal permeability of $0.1 \mathrm{md}$. The model average PI value was 0.003105 , and it is clear that RenardDupuy Anisotropic correlation PI is the closest value to the model average PI value. Figure-5 shows a comparison between PI values from the different Anisotropic correlations and model average value, using horizontal permeability values from 0.1 to $0.5 \mathrm{md}$. Renard-Dupuy correlation PI value remained to be the nearest value to the model average PI value.

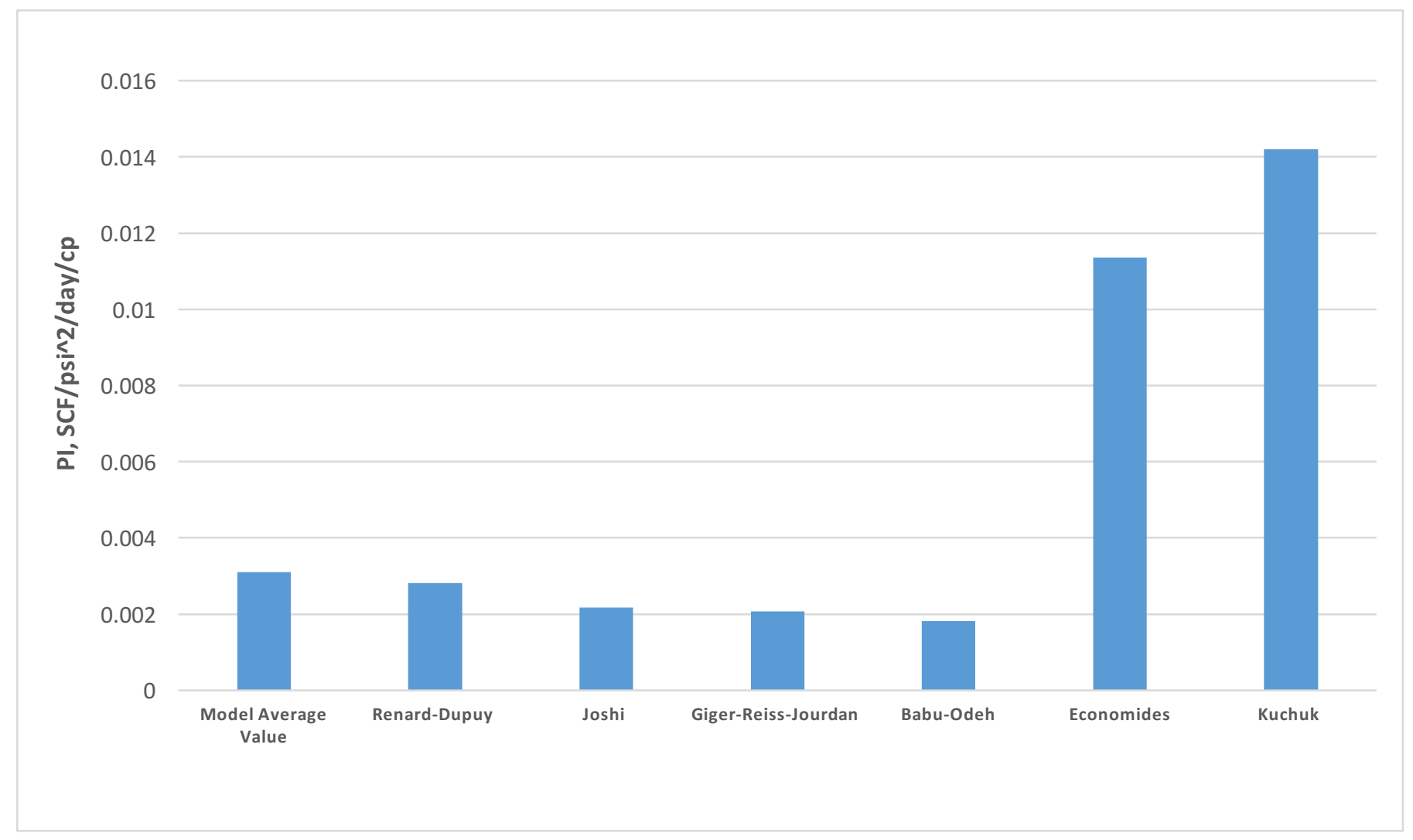

Figure 3. $P$ I for anisotropic method with $K_{h}=0.1 \mathrm{mD}$ values 
Figure-4 demonstrate better comparison of the PI values after taking off Economides and Kuchuk correlations that shows high values comparing with other correlations.

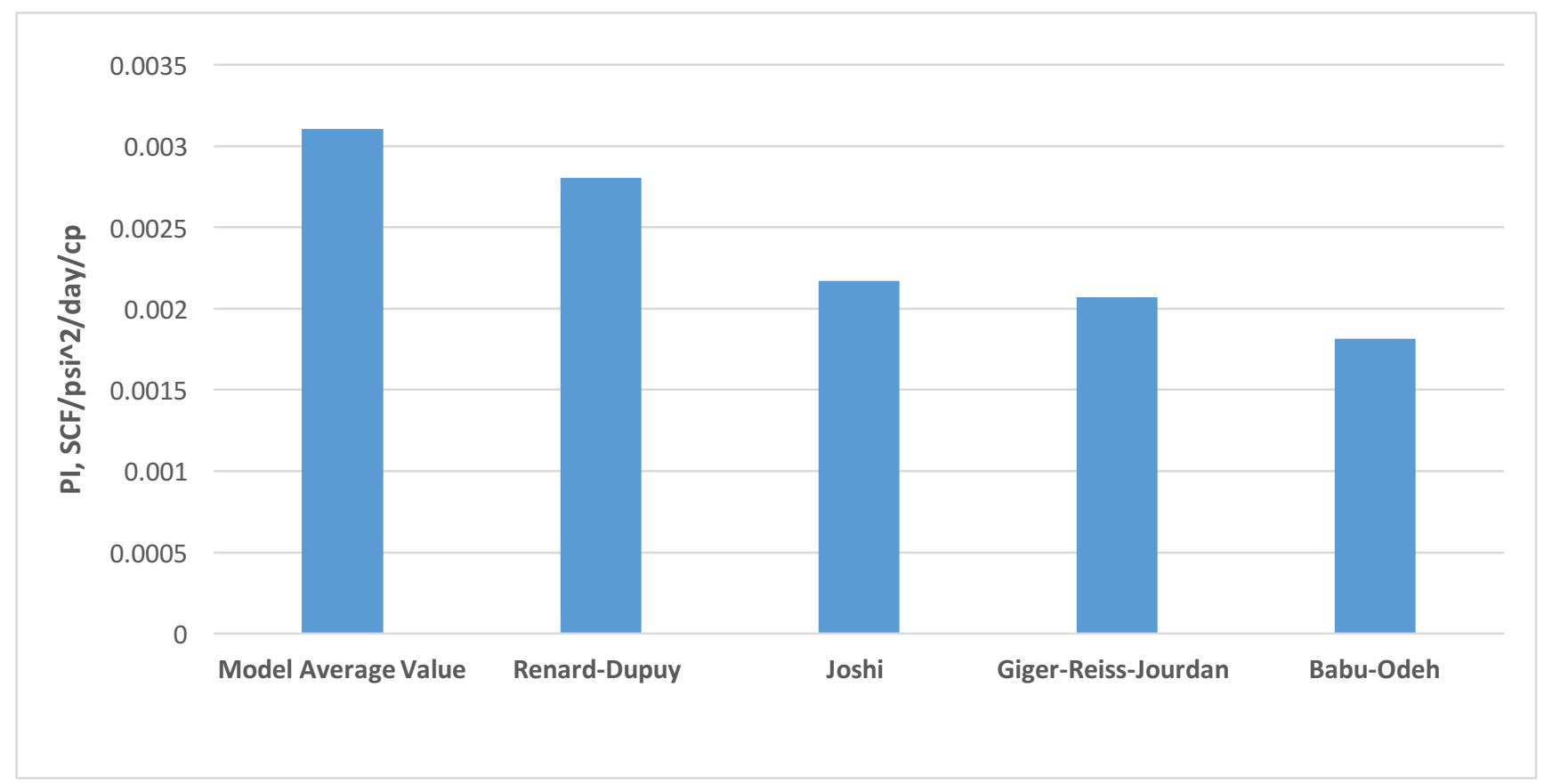

Figure 4. $P$ f for anisotropic method with $K_{h}=0.1 \mathrm{mD}$ values

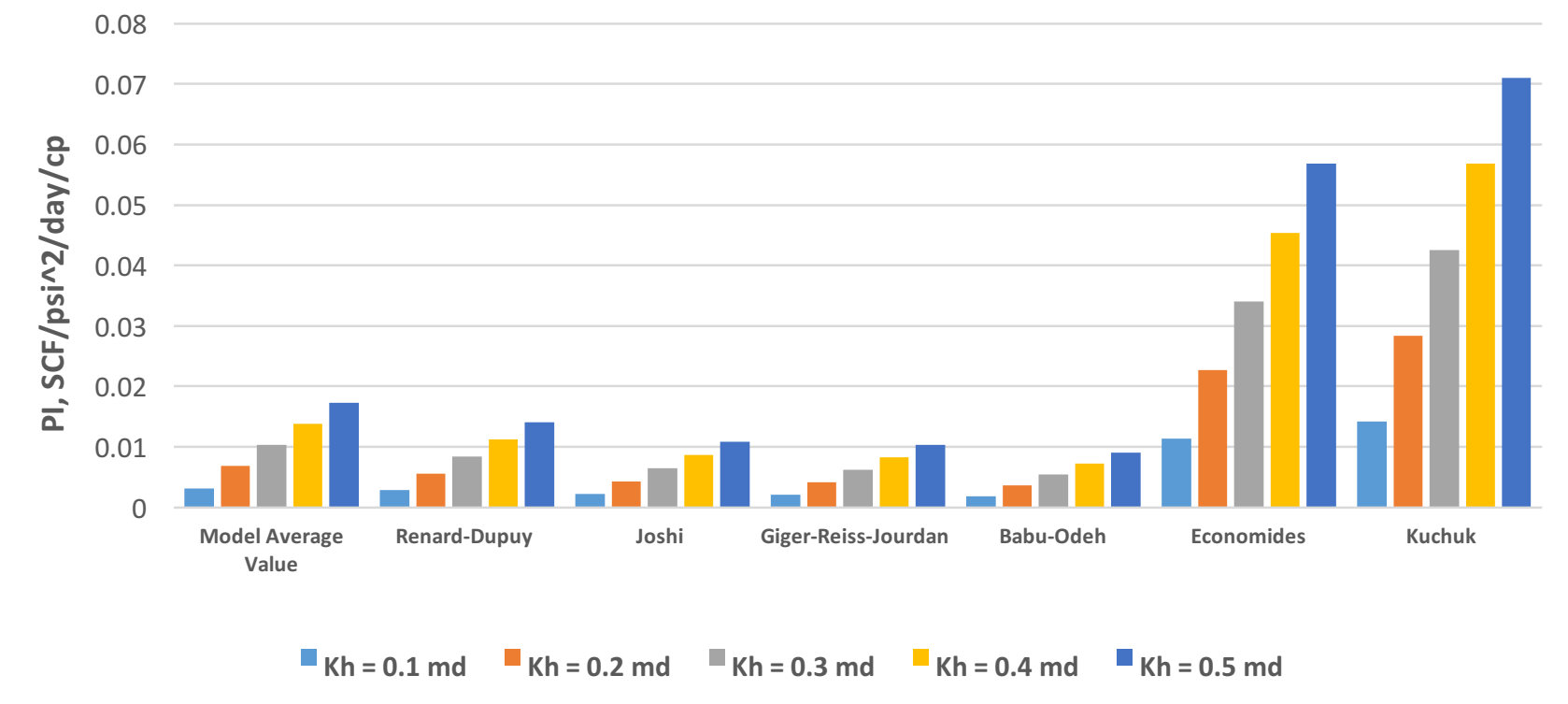

Figure 5. PI for different anisotropic method with $K_{h}$ values 


\subsubsection{Vertical Permeability}

PI values obtained from different correlations using vertical permeability range from 0.01 to $0.033 \mathrm{md}$, along with the average PI values obtained from the model. Figure- 6 \& 7 demonstrates the model average PI value and the PI values from the other correlations using a vertical permeability of $0.01 \mathrm{md}$. The model average PI value was 0.003105 , and it is clear that RenardDupuy Anisotropic correlation PI is the closest value to the model average PI value. Figure-8 shows a comparison between PI values from the different An-isotropic correlations and model average value, using vertical permeability values from 0.01 to $0.033 \mathrm{md}$. Renard-Dupuy correlation PI value remained to be the nearest value to the model average PI value.

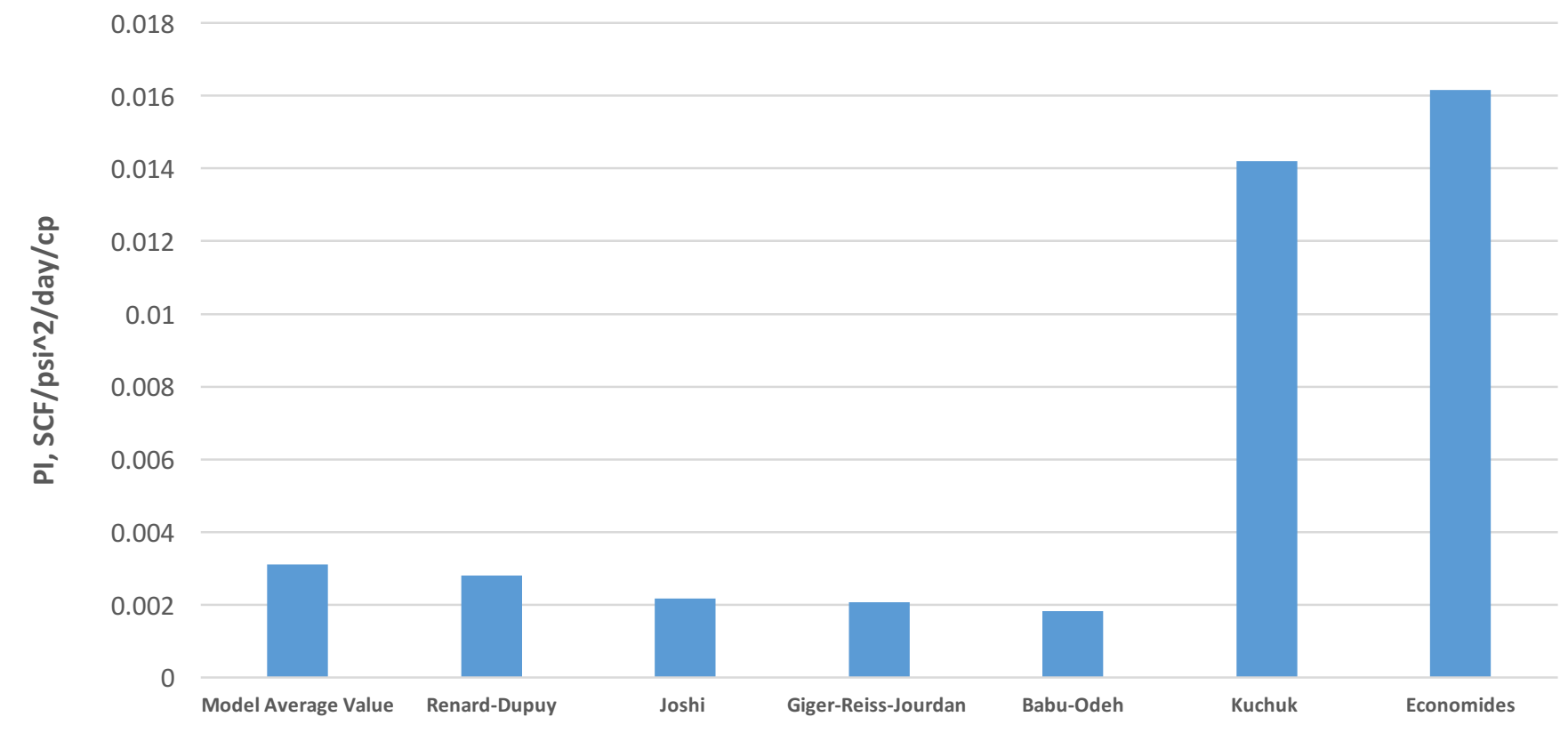

Figure 6. PI values for anisotropic method with $K_{v}=0.1 \mathrm{mD}$ 
Figure-7 demonstrate better comparison of the PI values after taking off Economides and Kuchuk correlations that shows high values comparing with other correlations.

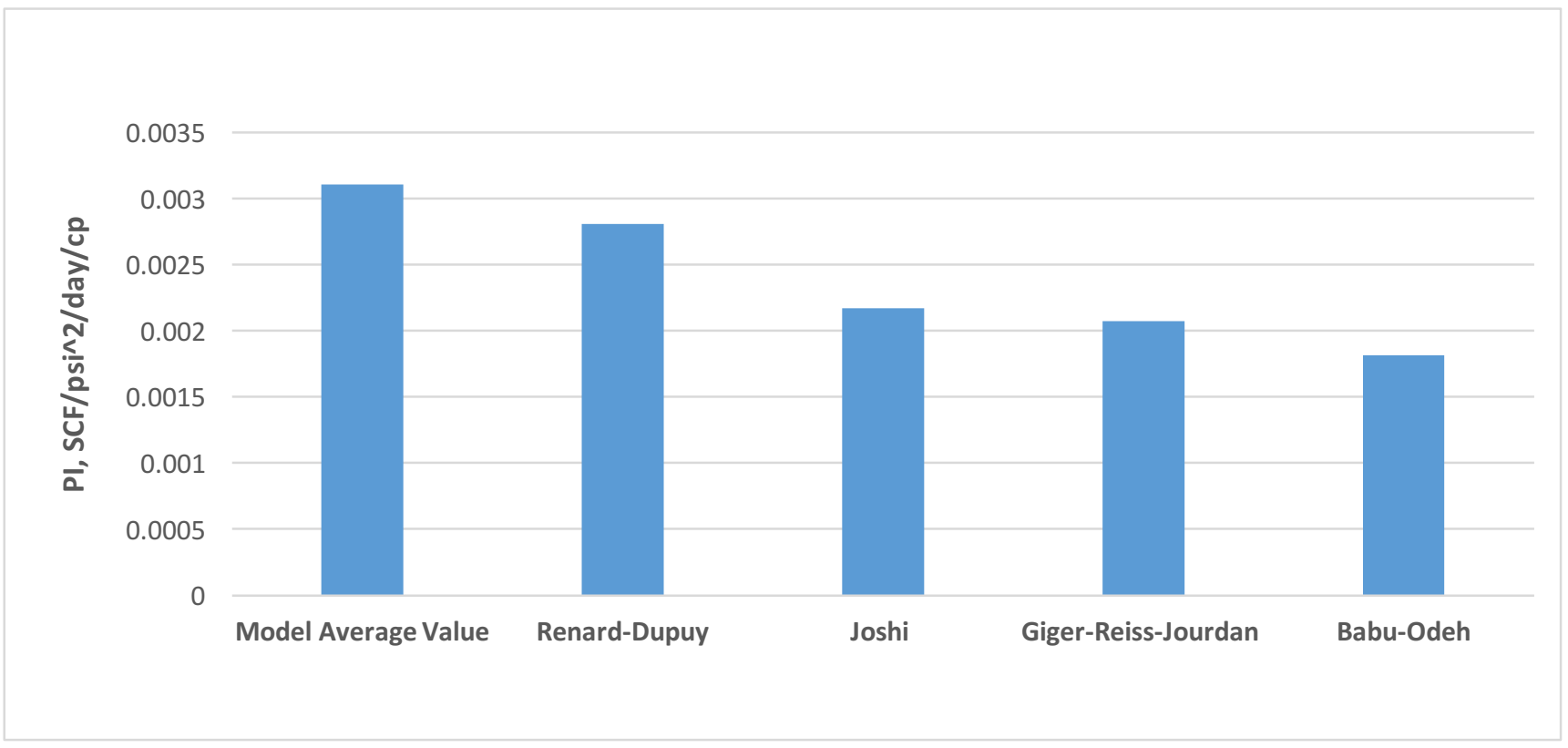

Figure 7. PI values for anisotropic method with $K_{v}=0.1 \mathrm{mD}$

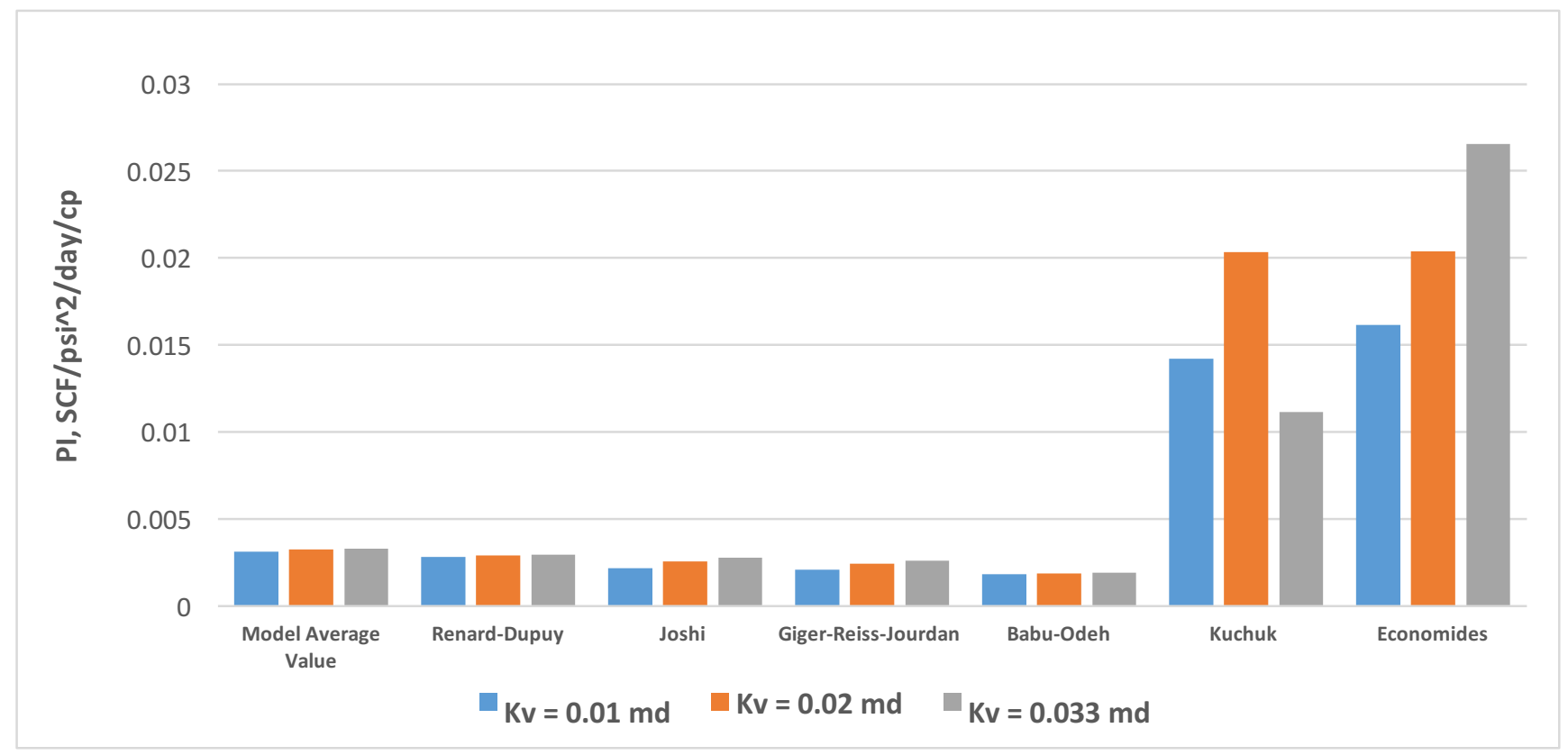

Figure 8. PI for anisotropic method with different $K_{v}$ values 


\subsubsection{Reservoir Thickness}

PI values obtained from different correlations using reservoir thickness range from 10 to $50 \mathrm{ft}$., along with the average PI values obtained from the model. Figure- $9 \& 10$ demonstrates the model average $\mathrm{PI}$ value and the $\mathrm{PI}$ values from the other correlations using a reservoir thickness of 10 $\mathrm{ft}$. The model average PI value was 0.00117, and It's clear that Renard-Dupuy An-isotropic correlation $\mathrm{PI}$ is the closest value to the model average $\mathrm{PI}$ value. Figure-11 shows a comparison between PI values from the different An-isotropic correlations and model average value, using reservoir thickness values from 10 to $50 \mathrm{ft}$. Renard-Dupuy correlation PI value remained to be the nearest value to the model average PI value.

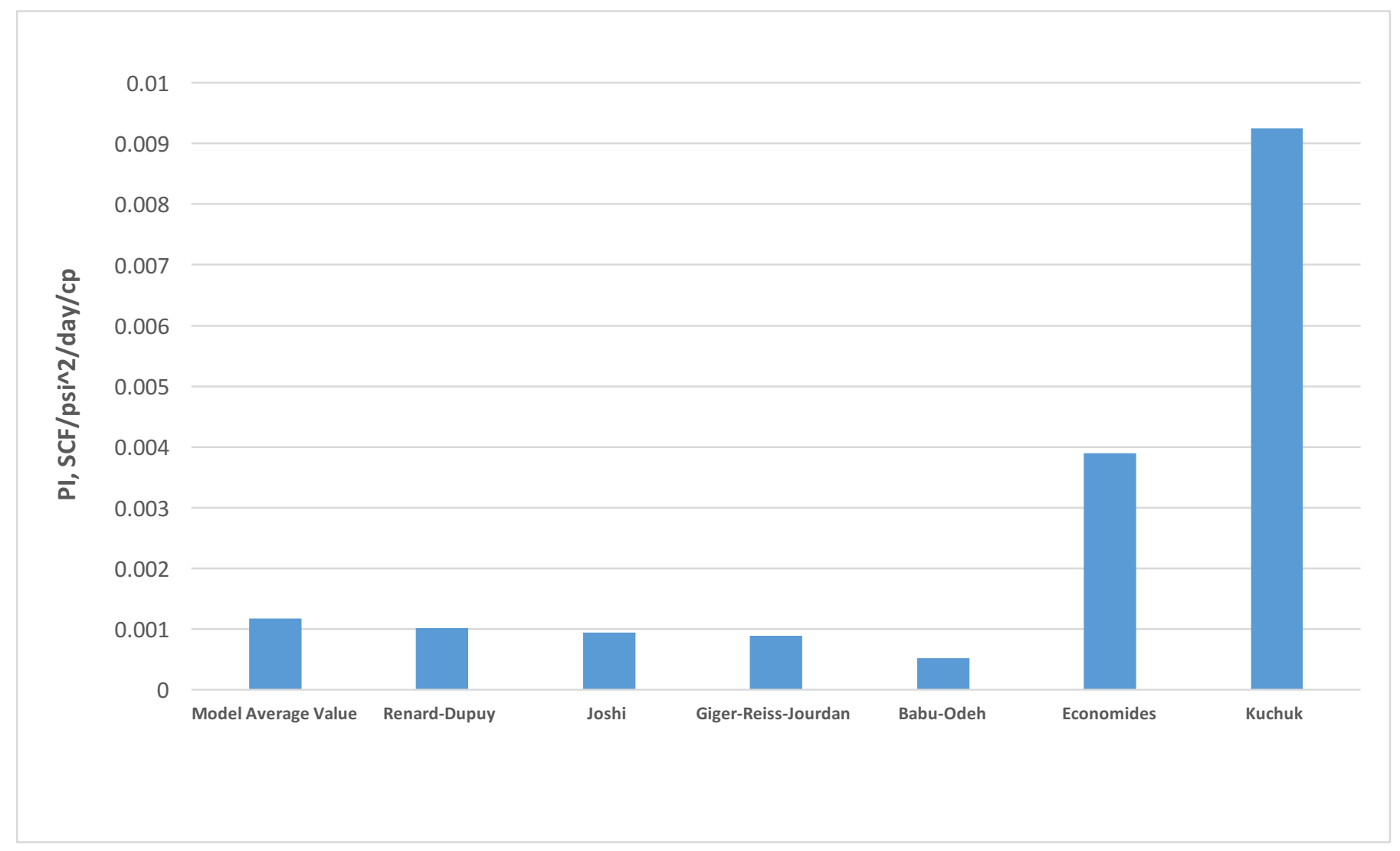

Figure 9. PI for anisotropic method with $h=10 \mathrm{ft}$. values 
Figure-10 demonstrate better comparison of the PI values after taking off Economides and Kuchuk correlations that shows high values comparing with other correlations.

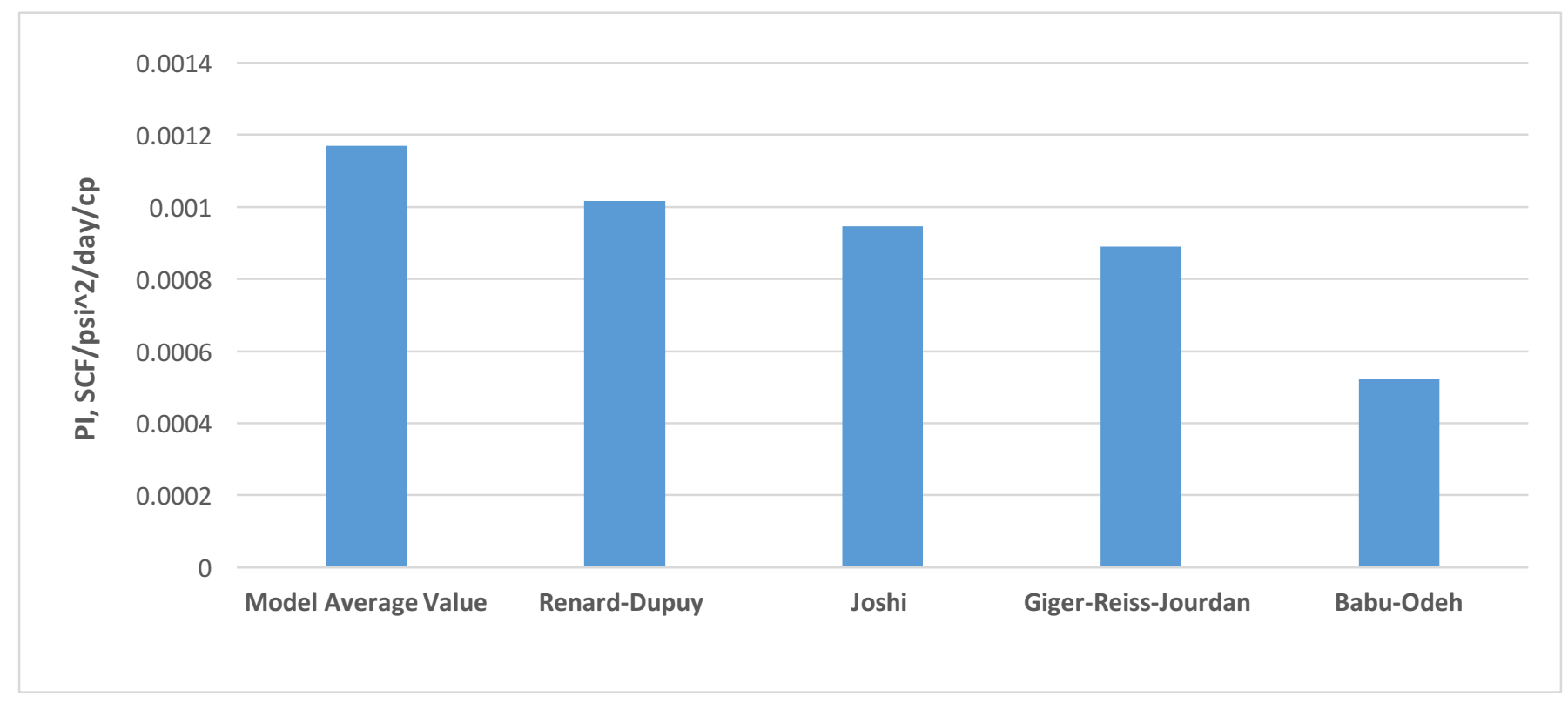

Figure 10. PI for anisotropic method with $h=10 \mathrm{ft}$. values

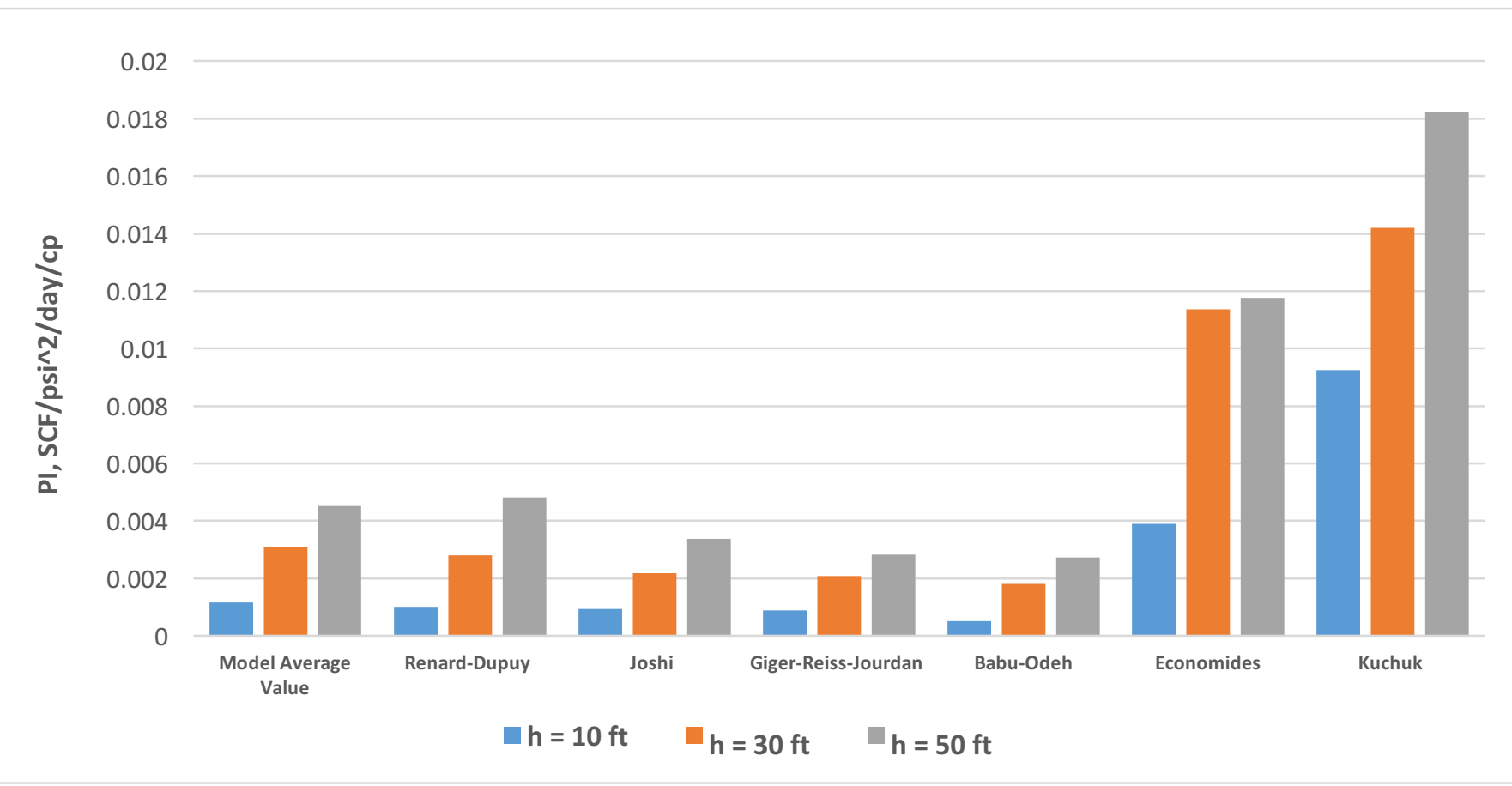

Figure 11. PI for different anisotropic method with Thickness values 


\subsubsection{Lateral Length}

PI values obtained from different correlations using lateral length range from 1000 to $2500 \mathrm{ft}$., along with the average PI values obtained from the model. Figure-12 \& 13 demonstrates the model average PI value and the PI values from the other correlations using a lateral length of $1000 \mathrm{ft}$. The model average PI value was 0.00173, and It's clear that Renard-Dupuy An-isotropic correlation $\mathrm{PI}$ is the closest value to the model average $\mathrm{PI}$ value. Figure-14 shows a comparison between PI values from the different An-isotropic correlations and model average value, using lateral length values from 1000 to $2500 \mathrm{ft}$. Renard-Dupuy correlation PI value remained to be the nearest value to the model average PI value.

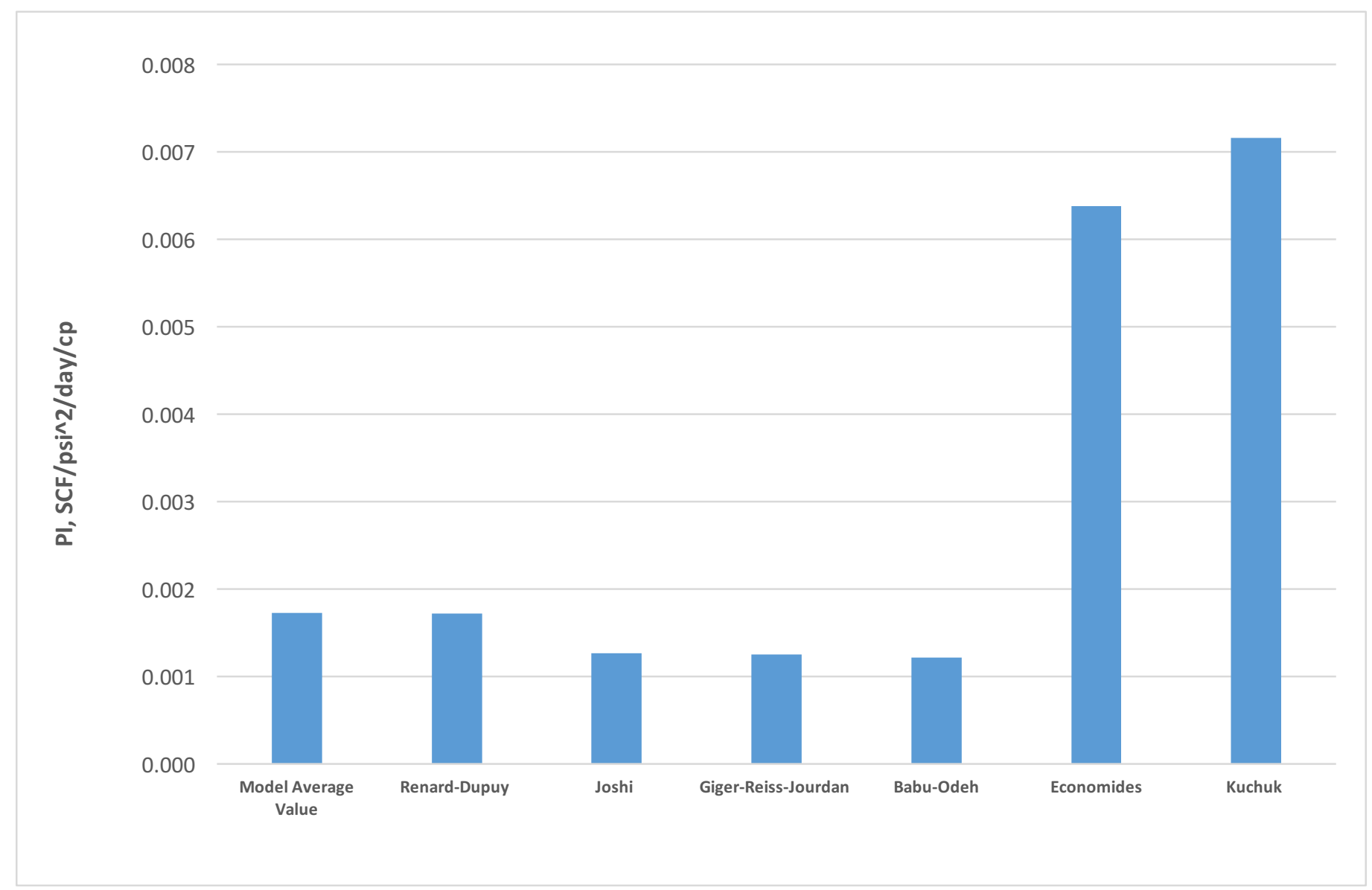

Figure 12. PI for anisotropic method with Lateral length $1000 \mathrm{ft}$. values 
Figure-13 demonstrate better comparison of the PI values after taking off Economides and Kuchuk correlations that shows high values comparing with other correlations.

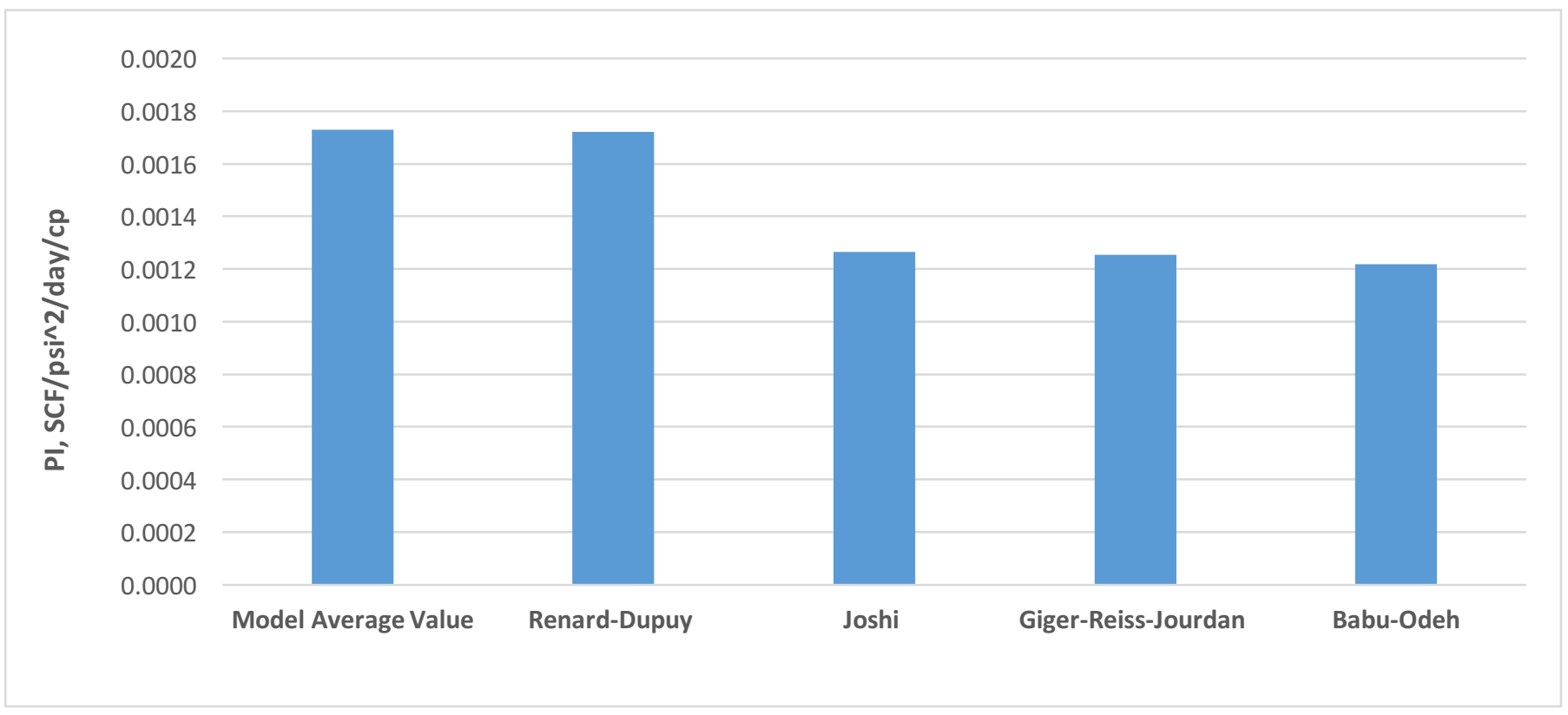

Figure 13. PI for anisotropic method with Lateral length $1000 \mathrm{ft}$. values

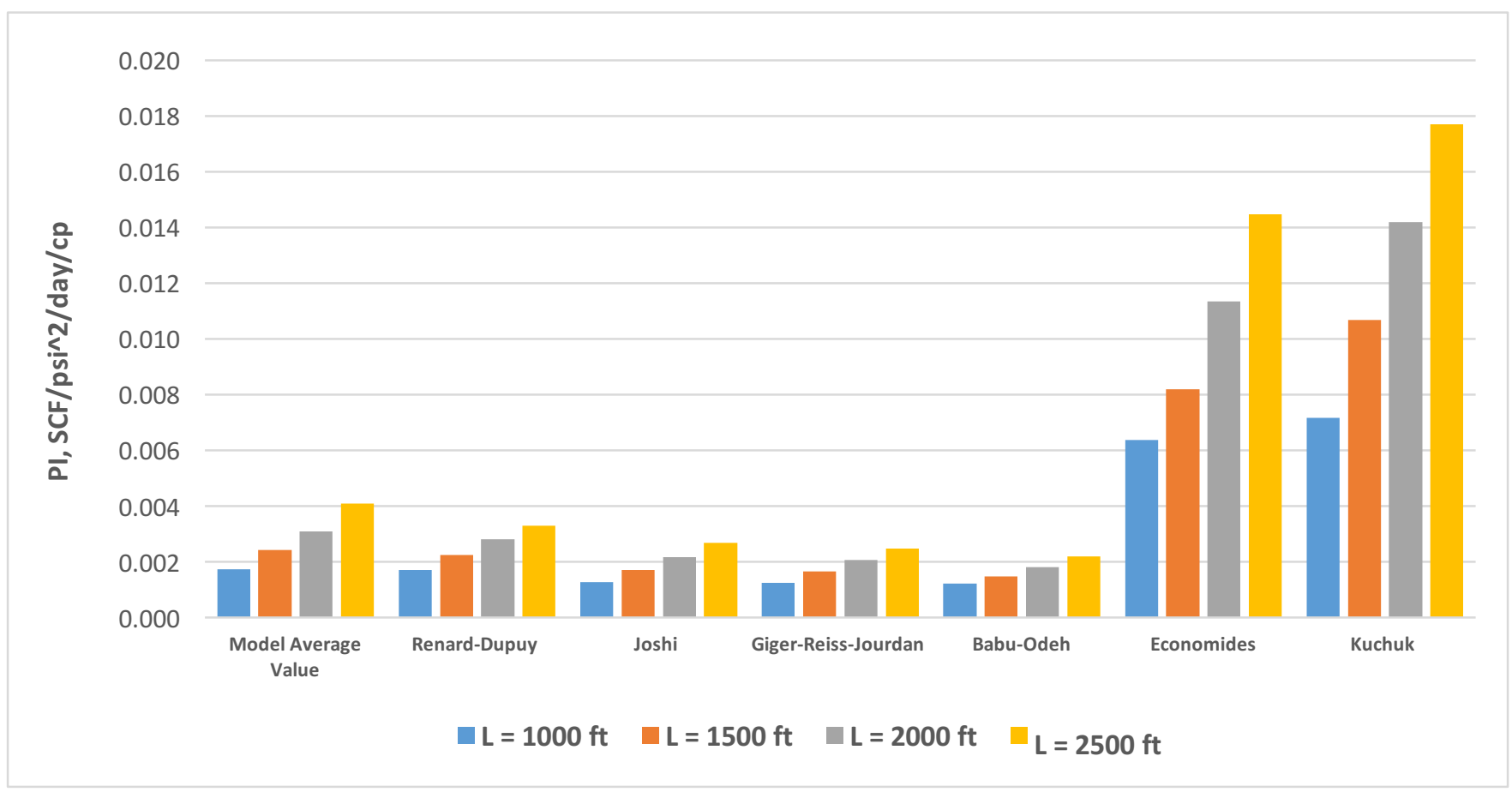

Figure 14. PI for different anisotropic method with Lateral Length values 


\section{CHAPTER 5: CONCLUSION}

The main purpose of this research is to evaluate and compare the productivity index of a horizontal well in a gas reservoir using a reservoir model and different steady state and pseudosteady state correlations. To achieve this objective, a numerical reservoir simulator (CMG) was used to construct the reservoir model and determine PI for a number cases (different values of horizontal permeability, vertical permeability, reservoir thickness, and lateral length). Later, the average model PI value was compared with the predicted values by the various correlations. The following conclusions were reached upon completion of this study:

1. Renard-Dupuy's anisotropic correlation consistently provided the closest agreement with the model average PI value in all cases investigated.

2. Kuchuk correlation resulted in the highest calculated value for PI.

3. Babu-Odeh correlation resulted in the lowest calculated value for PI.

Future work may include evaluation of the PI for a hydraulically fractured horizontal gas well with using the reservoir model and to attempt developing a correlation for PI. 


\section{REFERENCES}

1. Dankwa, Ohenewaa Kakra. Effects of Partial Completion on Productivity Index. Diss. African University of Science and Technology, 2011.

2. Babu, D. K., and Aziz S. Odeh. "Productivity of a Horizontal Well (includes associated papers 20306, 20307, 20394, 20403, 20799, 21307, 21610, 21611, 21623, 21624, 25295, 25408, 26262, 26281, 31025, and 31035)." SPE Reservoir Engineering 4.04 (1989): 417421.

3. Goode, P. A., and F. J. Kuchuk. "Inflow performance of horizontal wells." SPE Reservoir Engineering 6.03 (1991): 319-323.

4. Kuchuk, Fikri J., et al. "Pressure-transient analysis for horizontal wells." Journal of Petroleum Technology 42.08 (1990): 974-1.

5. Besson, J. "Performance of slanted and horizontal wells on an anisotropic medium." European Petroleum Conference. Society of Petroleum Engineers, 1990.

6. Joshi, S. D. "Augmentation of well productivity with slant and horizontal wells (includes associated papers 24547 and 25308)." Journal of Petroleum Technology 40.06 (1988): 729-739.

7. Giger, F. M. "Low-permeability reservoirs development using horizontal wells." Low Permeability Reservoirs Symposium. Society of Petroleum Engineers, 1987.

8. Saavedra, N. F., and S. D. Joshi. "Application of horizontal well technology in Colombia." SPE/CIM International Conference on Horizontal Well Technology. Society of Petroleum Engineers, 2000.

9. Odeh, Aziz S., and D. K. Babu. "Transient flow behavior of horizontal wells, pressure drawdown, and buildup analysis." SPE California Regional Meeting. Society of Petroleum Engineers, 1989.

10. Economides, M. J., C. W. Brand, and T. P. Frick. "Well configurations in anisotropic reservoirs." SPE Formation Evaluation 11.04 (1996): 257-262.

11. Saavedra, N. F., \& Joshi, S. D. (2000, January 1). Application of Horizontal Well Technology in Colombia. Society of Petroleum Engineers. doi:10.2118/65477-MS.

12. Escobar, F. H., Saavedra, N. F., Aranda, R. F., \& Herrera, J. F. (2004, January 1). An Improved Correlation to Estimate Productivity Index in Horizontal Wells. Society of Petroleum Engineers. doi:10.2118/88540-MS. 
13. Suk Kyoon, C., Ouyang, L.-B., \& Huang, W. S. B. (2008, January 1). A Comprehensive Comparative Study on Analytical PI/IPR Correlations. Society of Petroleum Engineers. doi:10.2118/116580-MS.

14. Dankwa, O. K., \& Igbokoyi, A. O. (2012, January 1). Effects of Partial Completion on Productivity Index. Society of Petroleum Engineers. doi:10.2118/163030-MS.

15. Alarifi, S., AlNuaim, S., \& Abdulraheem, A. (2015, March 8). Productivity Index Prediction for Oil Horizontal Wells Using Different Artificial Intelligence Techniques. Society of Petroleum Engineers. doi:10.2118/172729-MS. 


\section{APPENDIX}

\section{CMG Model}

CMG (computer Modeling Group) is one of the largest providers of reservoir simulation software in the world which was originated in 1978. In this research, CMG-IMEX model was used to evaluate the correlation for horizontal well productivity index in a gas reservoir. The model started by clicking on the Builder icon on the CMG technologies launcher as shown in Figure-3.

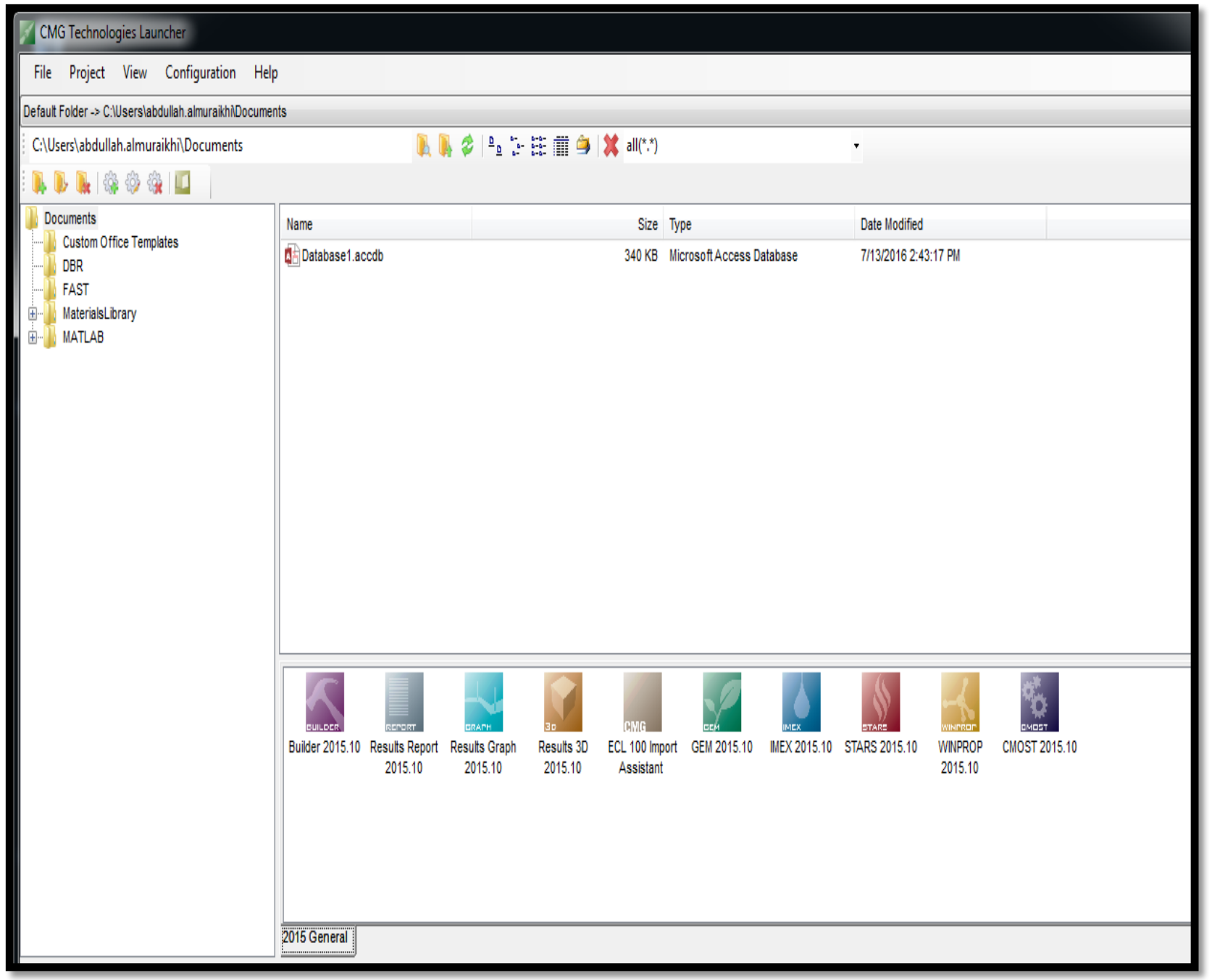

Figure 15. CMG launcher 
The user selects IMEX simulator, Field units, Single porosity, and simulation start date as shown in Figure-4.

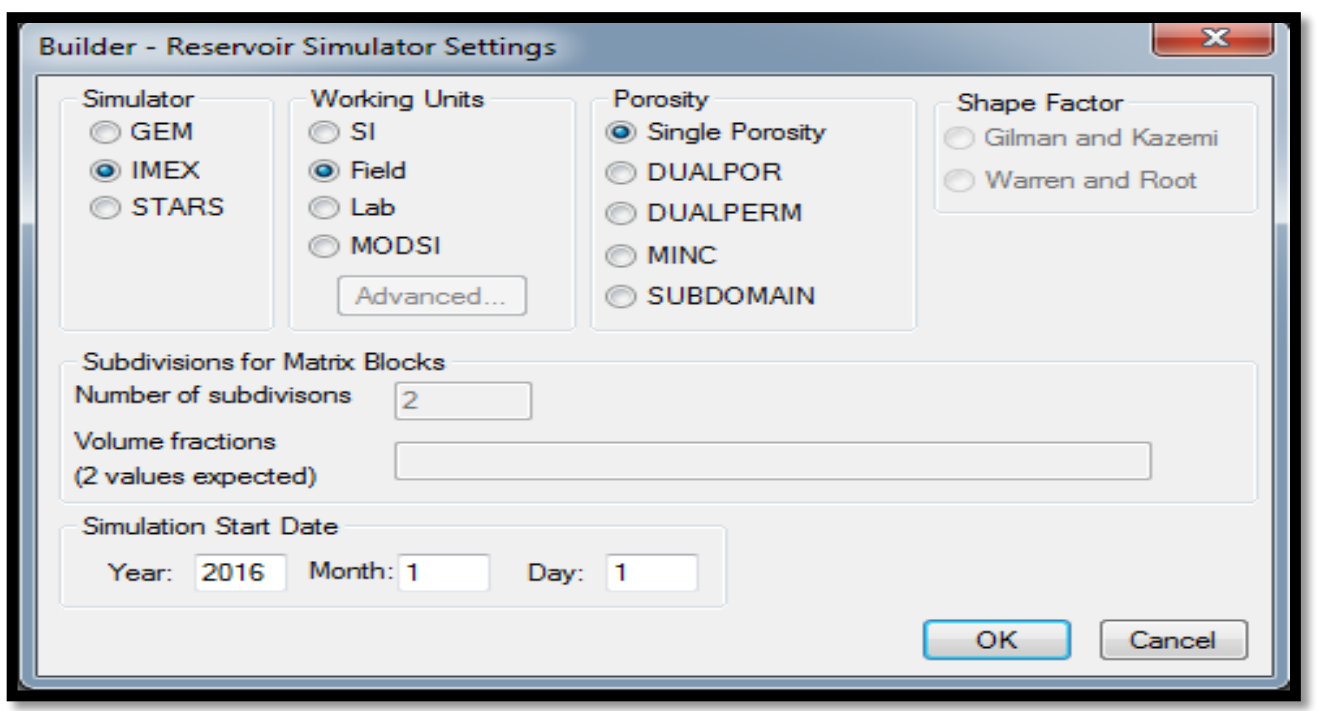

Figure 16. Reservoir simulation setting

The user is able to view the CMG BUILDER by clicking "OK" as shown in Figure-5.

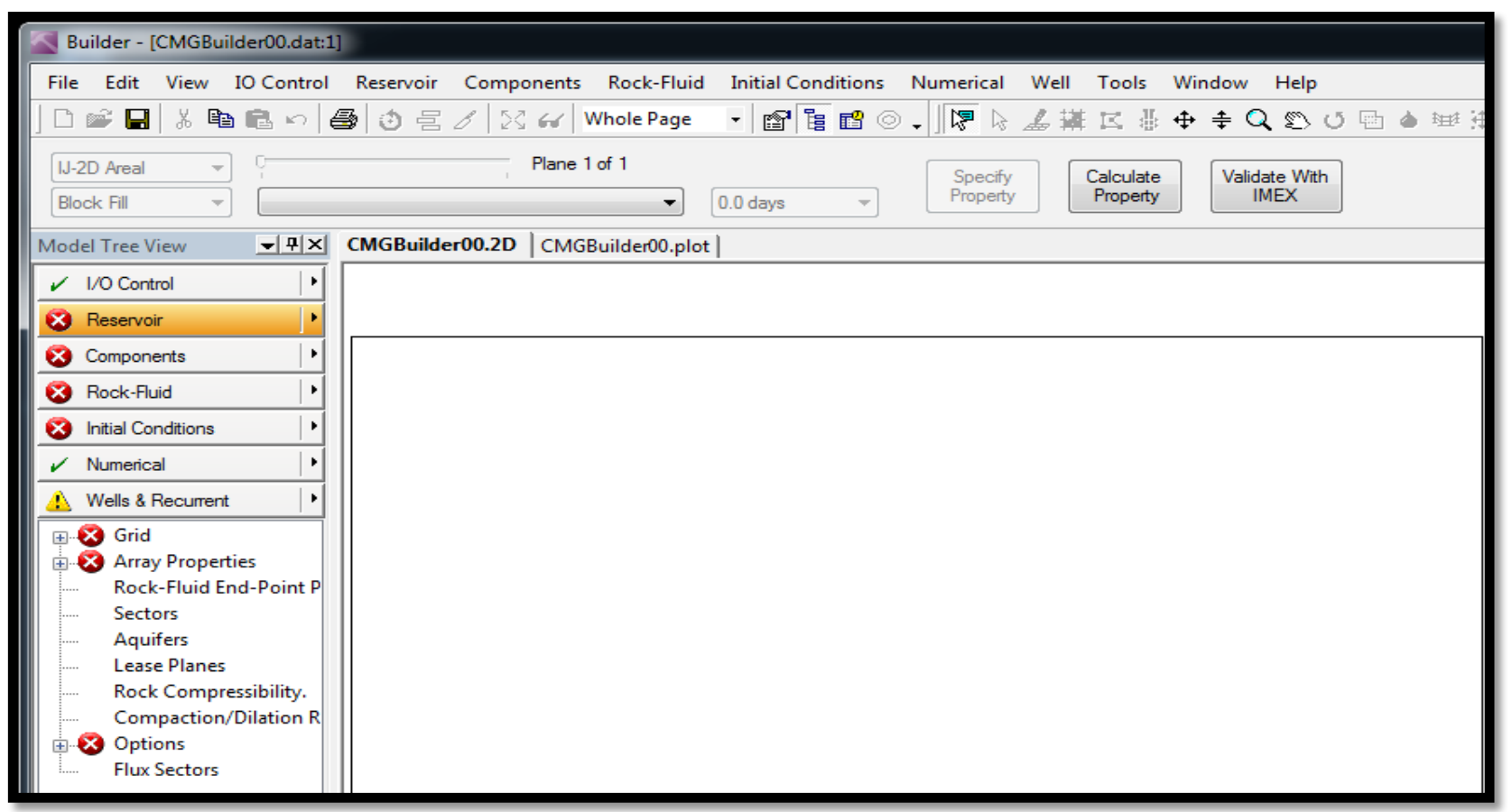

Figure 17. CMG Builder 
The user clicks on the "Reservoir" tab in the model tree view and selects "Create grid" and then "Cartesian". The user inputs the number of grid blocks in the I-direction, J- direction, and Kdirection as shown in Figure-6.

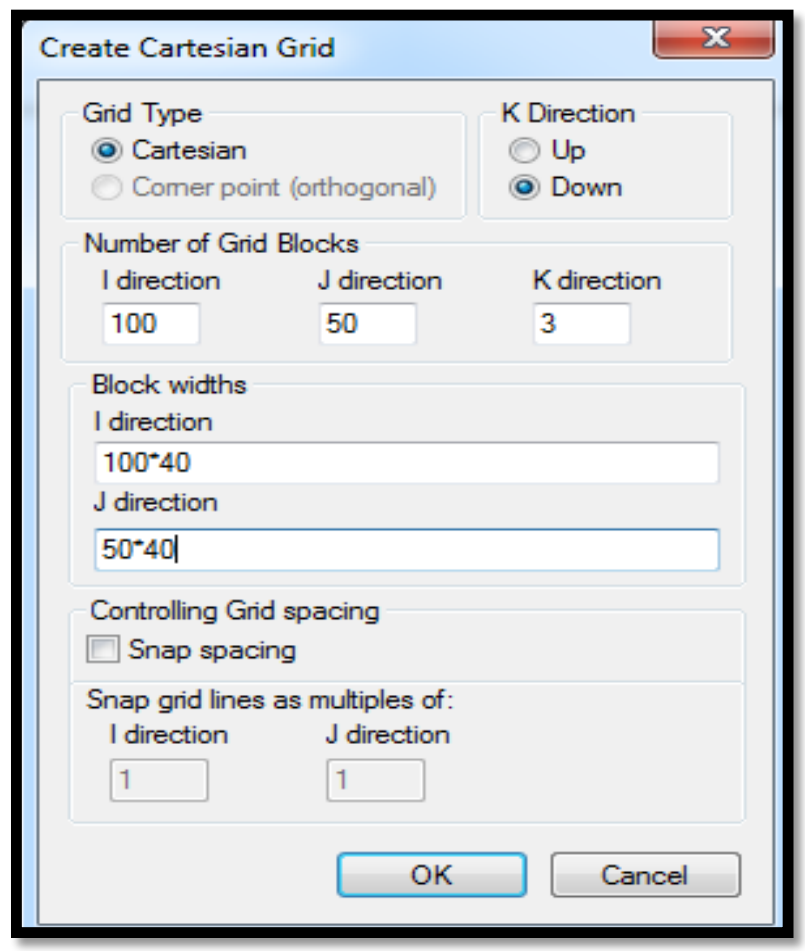

Figure 18. CMG Builder

The user selects the "Specify Property" tab and input the values including grid top, grid thickness, porosity, matrix permeability (I, J, and K-directions). "General Property Specification" screen is shown in Figure-7.

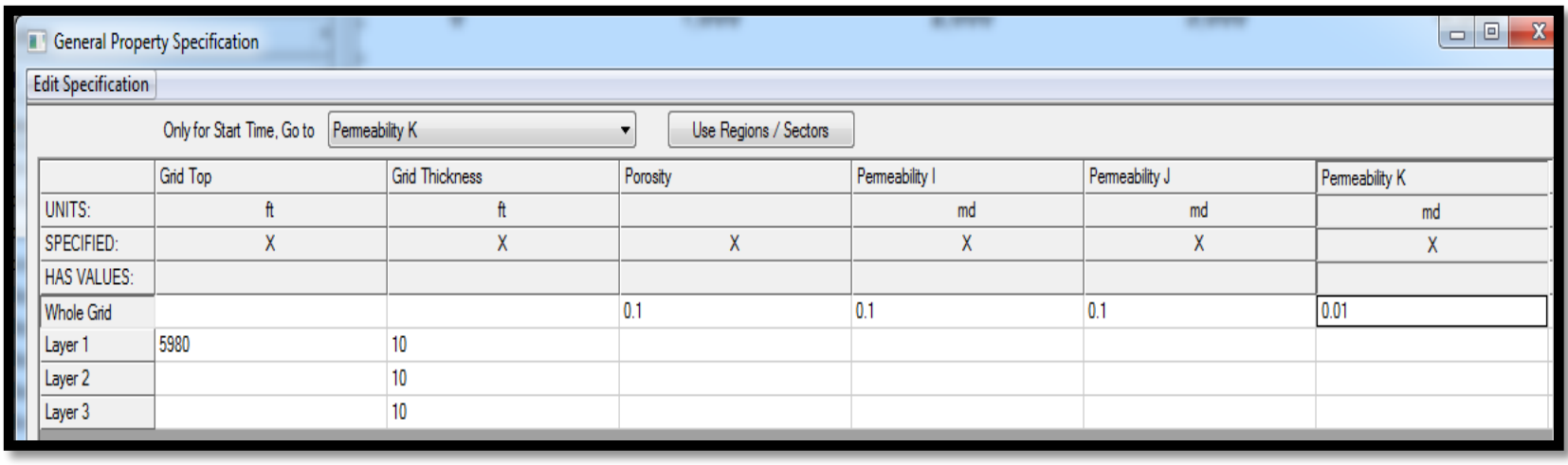

Figure 19. General Property Specification 
The user double clicks on "Rock compressibility" from the reservoir section and inputs the reference pressure for (CPOR) \& (PRPOR) as shown in Figure-8

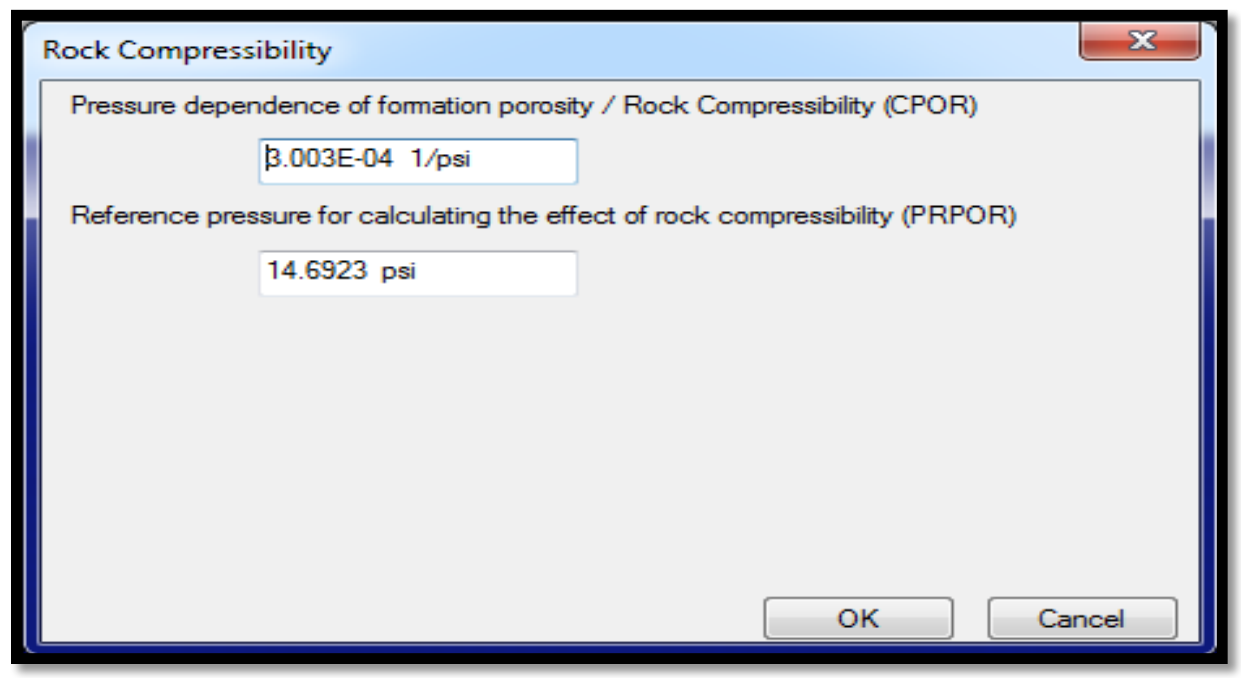

Figure 20. Rock compressibility

The user double clicks on "Imwx PVT Regions" from initial condition section and inputs reservoir pressure, and gas gravity as shown in Figure-9.

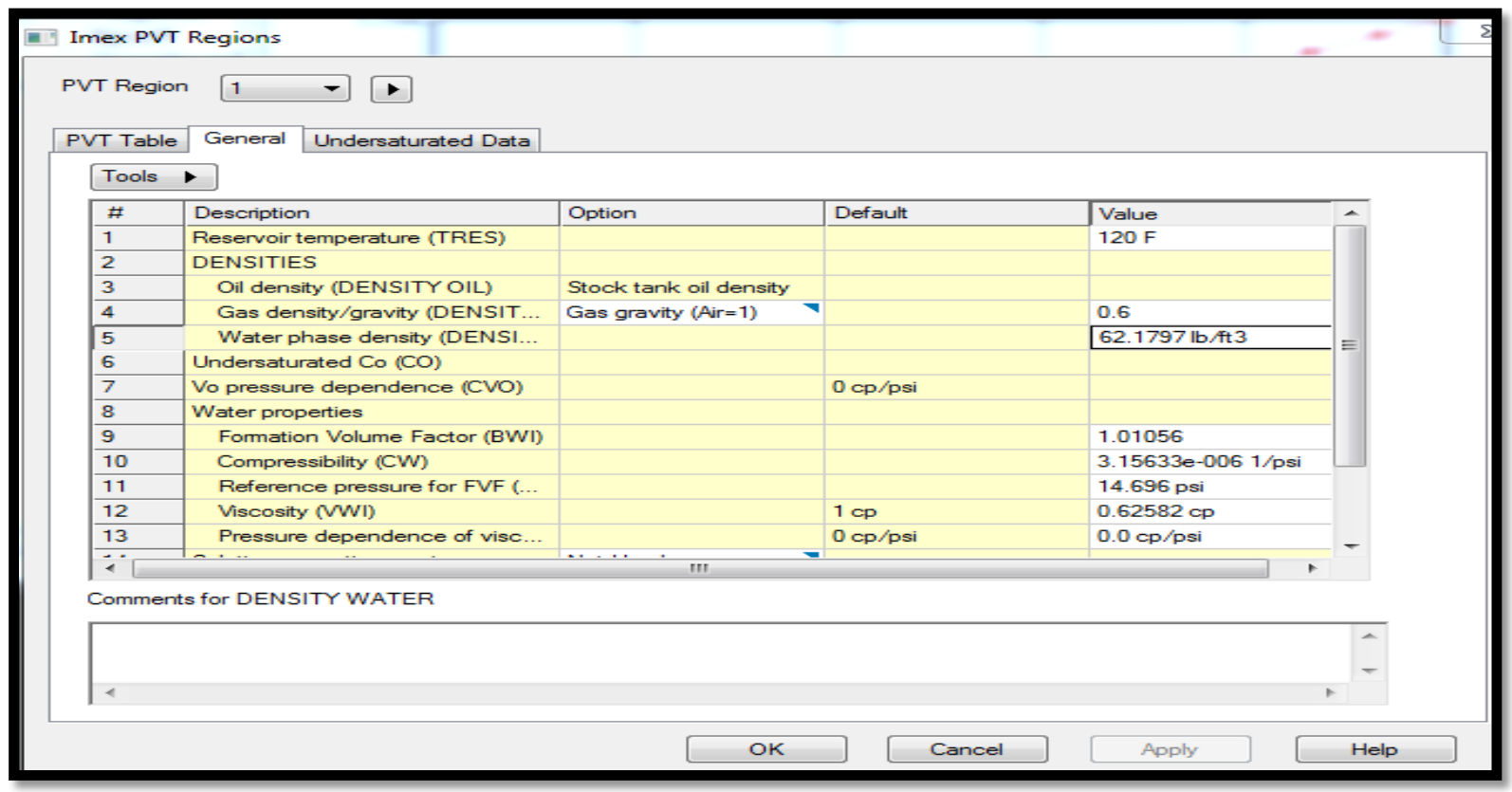

Figure 21. Imwx PVT Regions 
The user clicks on the "Rock types" tab in the model tree view and relative permeability table.

Then the user selects include capillary pressure as shown in Figure-10.

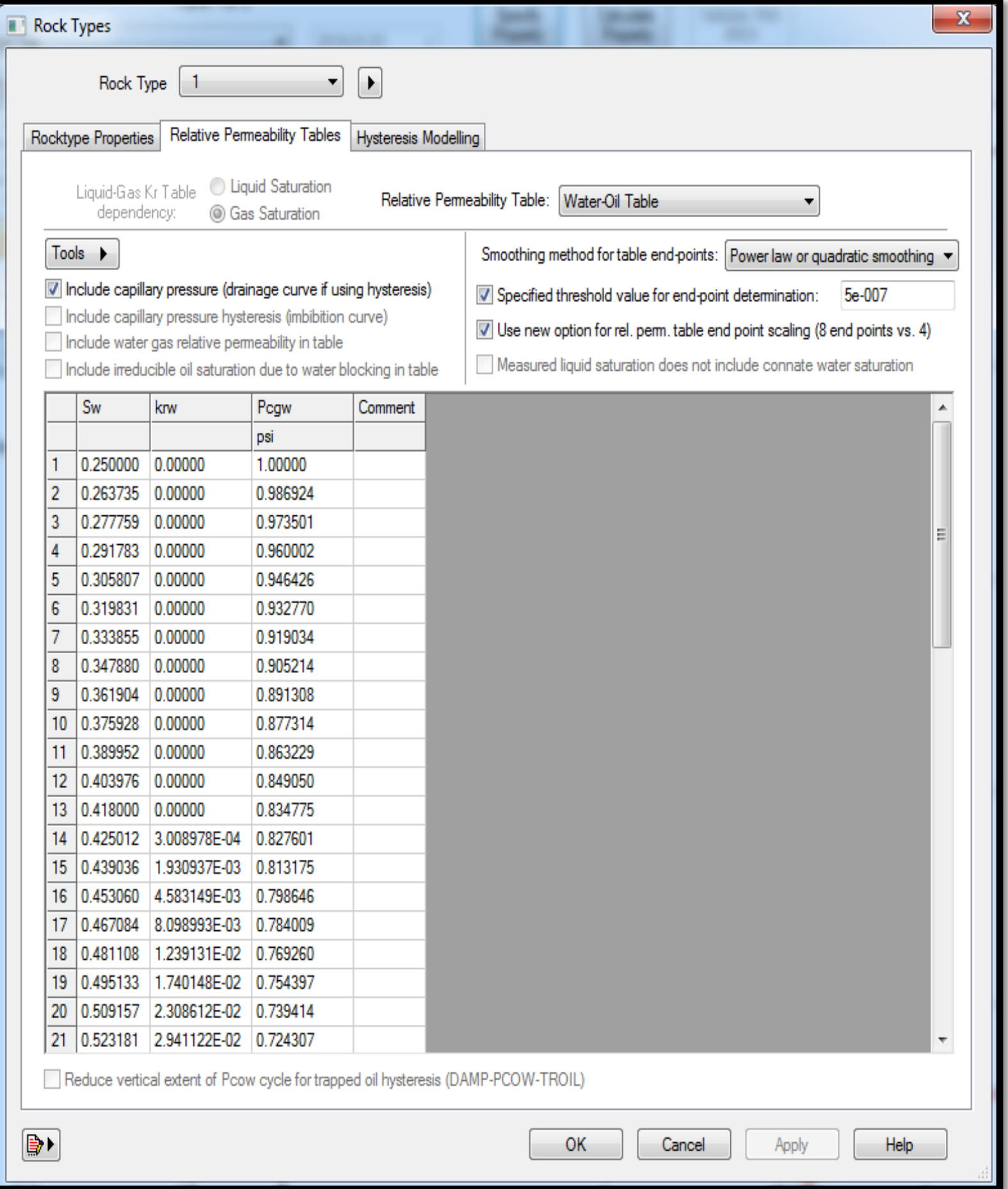

Figure 22. Rock type 


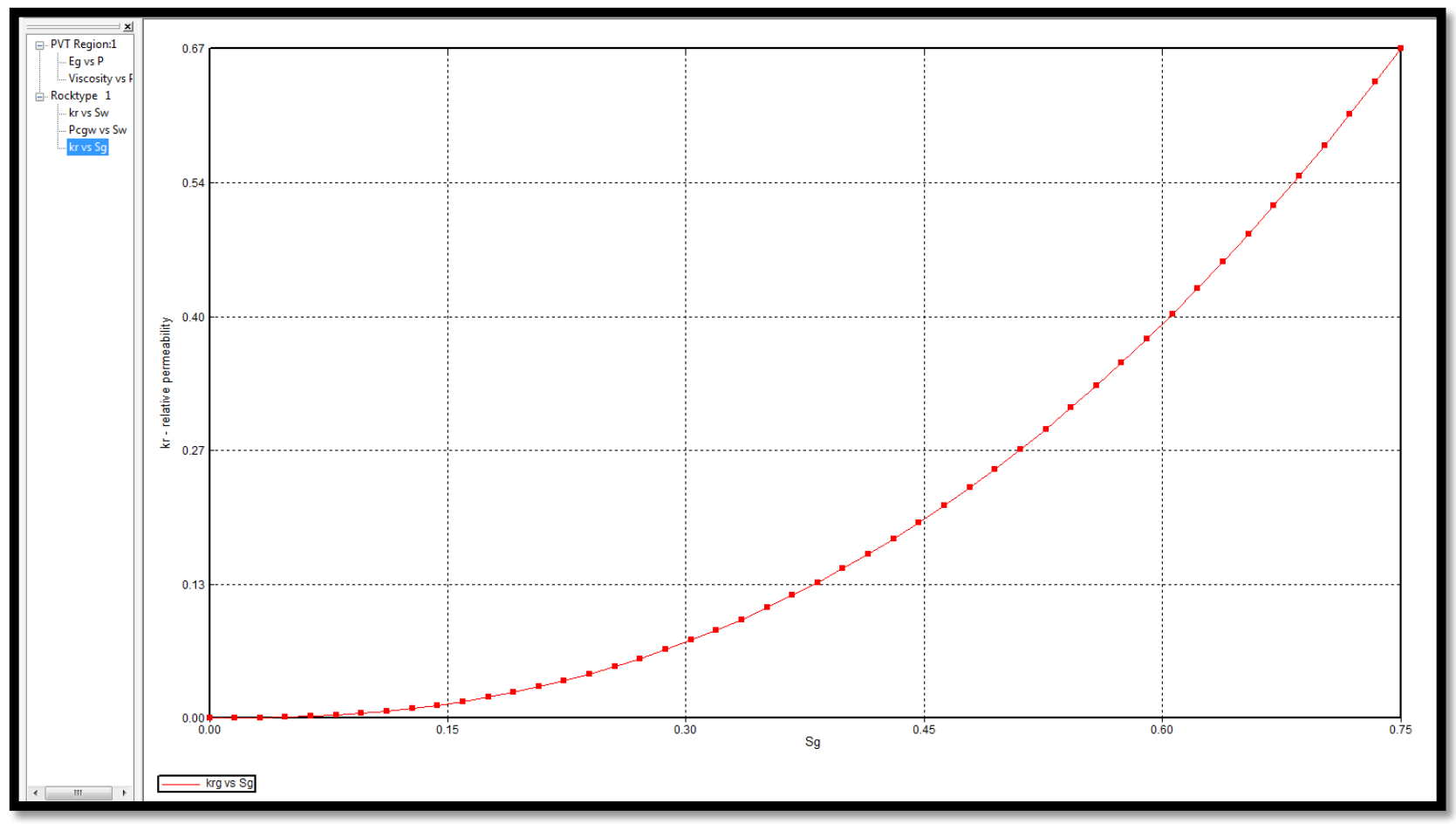

Figure 23. Kr Vs. Sg

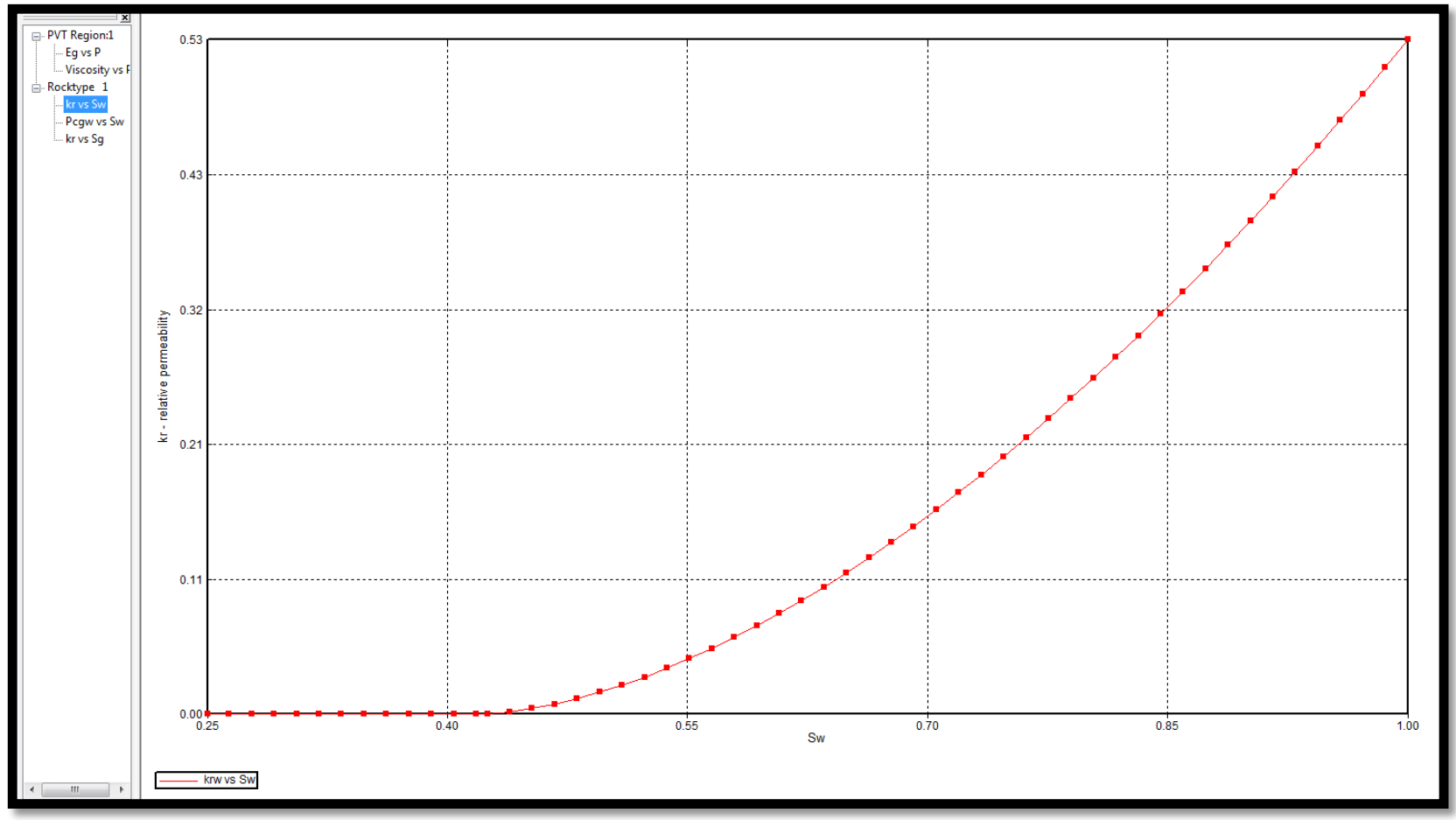

Figure 24. Kr Vs. Sw 
The user clicks on the "Initial Condition" tab in the model tree view and picks Initialization Setting then the user selects "water gas" from the "Calculation Method" tab as shown in Figure-13.

nitial Conditions

Calculation Methods

PVT Region Parameters Advanced Parameters

Block Saturation at each grid block average over the depth interval spanned by the grid block (VERTICAL DEPTH_AVE)

-Pefform Gravity-Capillary Equilibrium of A Reservoir Initially Containing

Water, Oil, Gas (WATER_OIL_GAS)

Water, Oil (WATER_OIL) - No free gas

(2) Water,Gas (WATER_GAS)

Water-Gas Zone Transition

Use water-gas capillary pressure curves and determine water-gas transition zone. (TRANZONE)

(†) Ignore ALL capillary pressure curves. ( NOTRANZONE)

Phase Pressure Correction

() Add phase pressure correction to ensure that the reservoir is initially in gravitational equilibrium. ( $E Q U I L$ )

Do not add a phase pressure correction. (NOEQUIL)

(2) Block Saturation at each grid block same as saturation prevaling at the block center (VERTICAL BLOCK_CENTER)

Perform Gravity-Capillary Equilibrium of A Reservoir Initially Containing

Water, Oil, Gas (WATER_OIL_GAS)

Water, Oil (WATER_OIL) - No free gas

(2) Water, Gas (WATER_GAS)

User specified pressure and saturations for each grid block (USER_INPUT)

(Pressure and saturations at each grid block must be specified by the user under the PRES, SW, S0 keywords.)

临,

$\mathrm{OK}$

Cancel

Apply

Help

Figure 25. Initial condition 
Then the user goes to "PVT Region Parameters" tab and enters the reference pressure, reference depth, and water gas contact as shown in Figure-14.

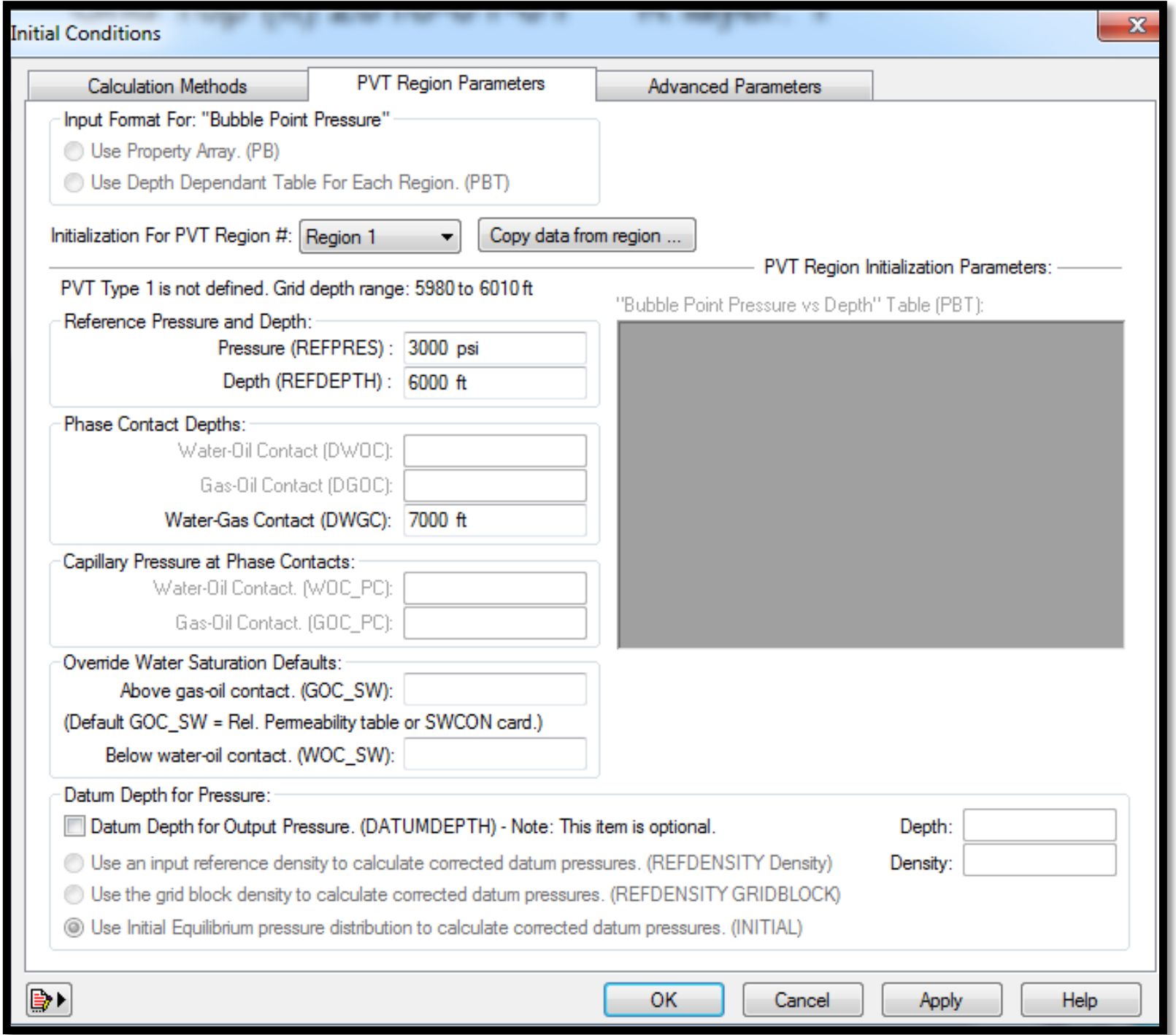

Figure 26. Initial condition 
The user clicks on the "Wells \& Recurrent" tab in the model tree view and creates new well by right clicking on Wells and select New. This will allow the user to create a new well and the user gives a name "Horizontal" and selects type as "Producer" in Figure-15.

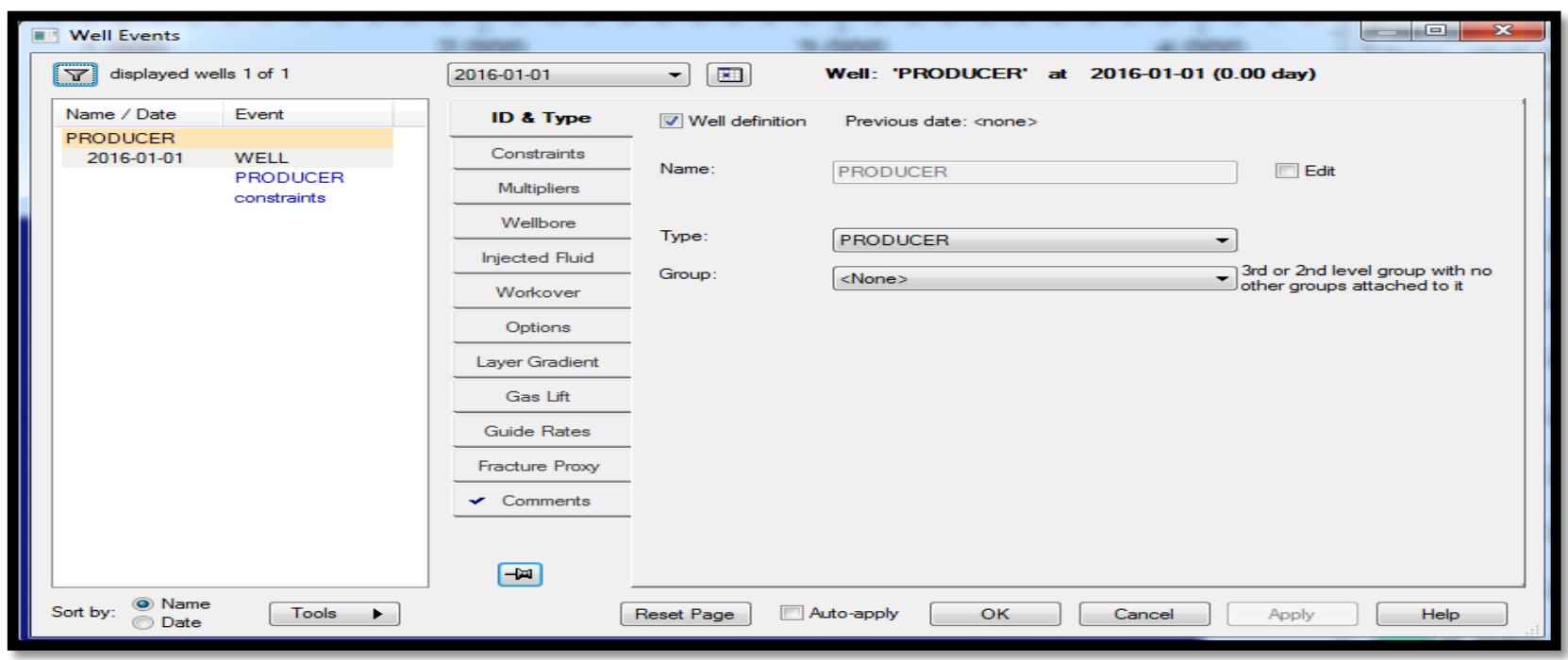

Figure 27. Well events

The user clicks on "Constraints" tab and checks the box for Constraint definition. In addition, the user selects new (in the Constraint column of the table), selects OPERATE. Then the user selects BHP bottomhole pressure, MIN, to any pressure as shown in Figure-16.

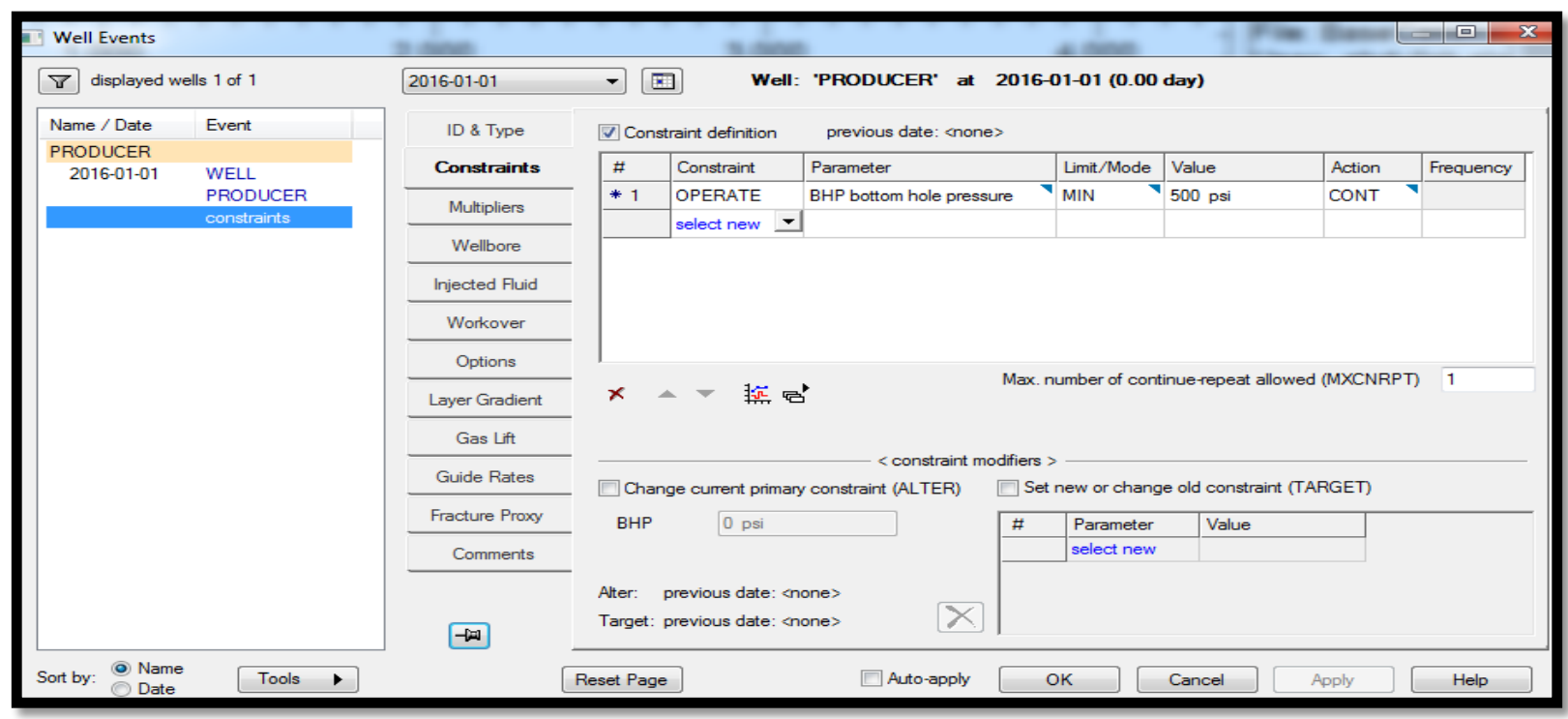

Figure 28. Well events 
The user double clicks on "PERF" and selects the general tab and fills out the information including direction, and radius of the wellbore as shown in Figure-17.

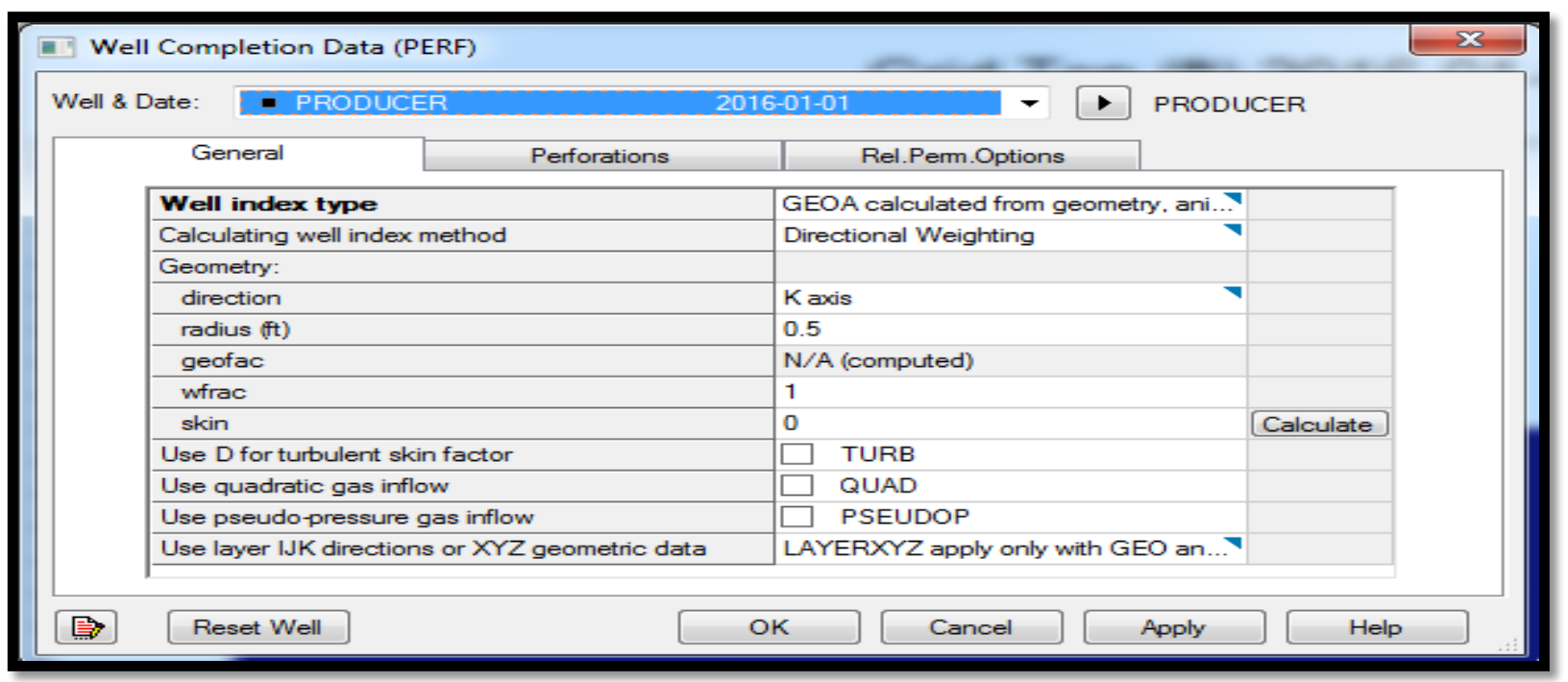

Figure 29. Well completion data

The user selects the perforation tab and to add perforation with the mouse, the user presses button and picks the blocks for perforations as shown in Figure-18.

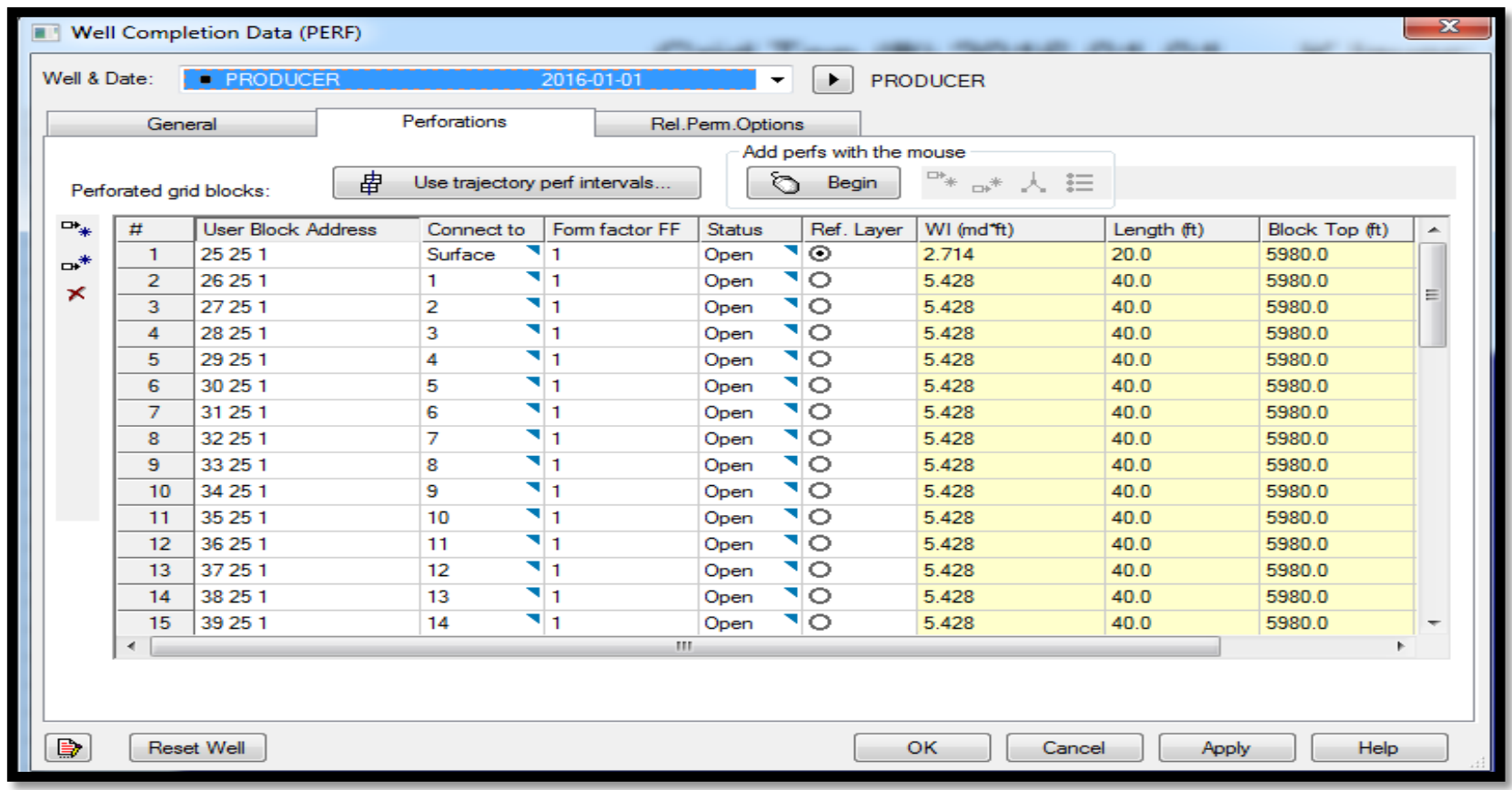

Figure 30. Well completion data 
This is the top view of the reservoir with everything completed as shown in Figure-19.

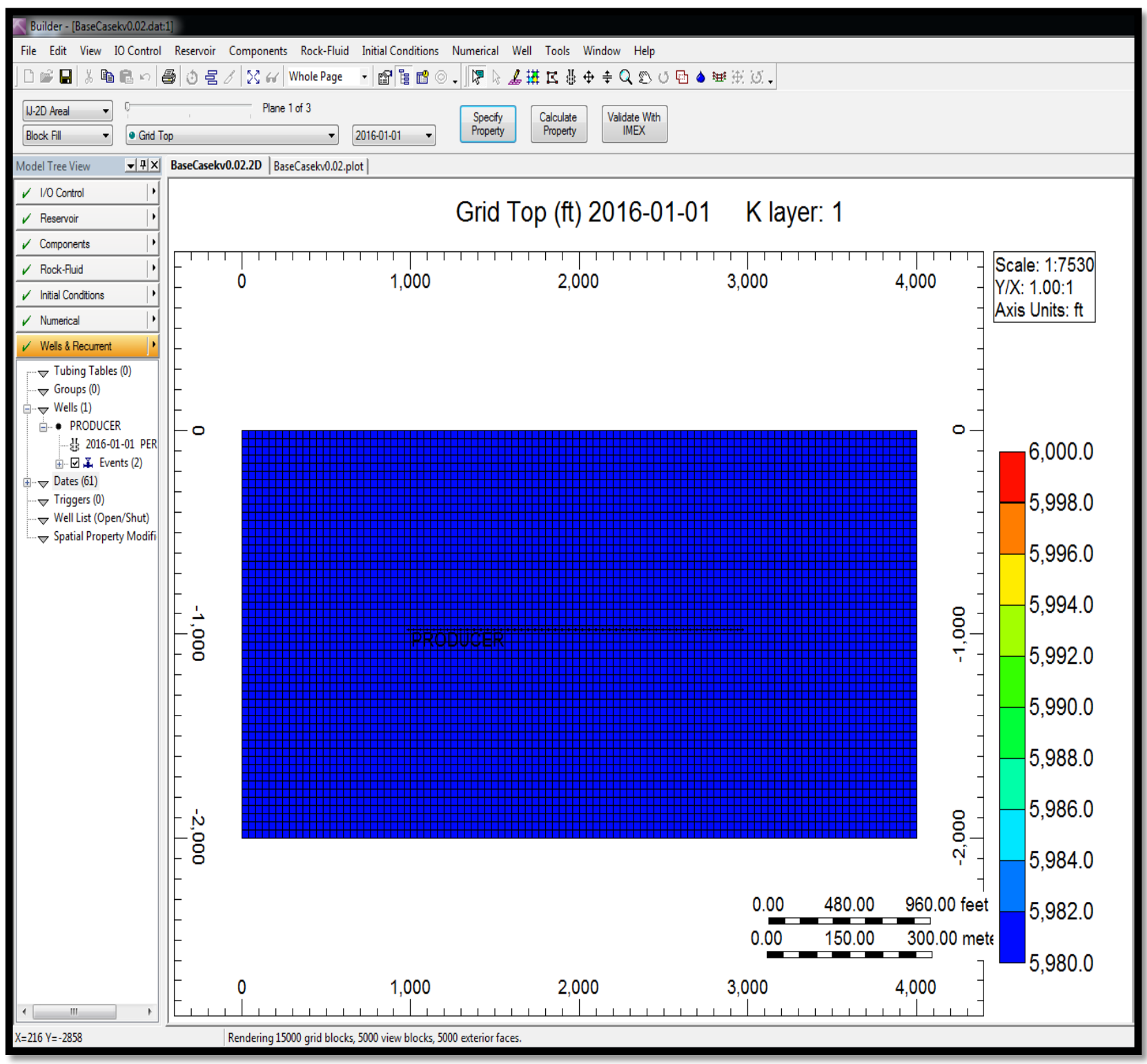

Figure 31. Top view 